\title{
SUBSEA PIPELINE WALKING WITH VELOCITY DEPENDENT SEABED FRICTION
}

1. Indranil Guha

PhD Candidate - UWA

Construction Engineer / Pipeline Project Manager

Shell Offshore Services B.V.

Karachaganak Petroleum Operating B.V., Kazakhstan

Email: Indranil.guha@shell.com

2. David J. White

Professor of Infrastructure Geotechnics

Engineering and the Environment

University of Southampton, Highfield, Southampton, SO17 1BJ, UK

Also affiliated with the University of Western Australia

Email: david.white@soton.ac.uk

3. Mark F Randolph

Professor

Fugro Chair in Geotechnics, Centre for Offshore Foundation Systems University of Western Australia

35 Stirling Highway, Crawley

WA 6009, Australia

Email: mark.randolph@uwa.edu.au 


\begin{abstract}
With the increase in demand and supply gap in the oil and gas industry, new developments of oil and gas infrastructure are moving into deeper water. This requires design and construction of long high temperature and high pressure pipelines from deep sea to shore. These pipelines are subjected to cyclic expansion during operating cycles. Accumulated axial movement due to repeated thermal cycles may lead to global displacement referred to as 'walking'. Walking rates depend on the restraint associated with seabed friction. In conventional analyses, seabed friction is independent of the rate of thermal loading and expansion but it has been recognised that the sliding resistance between a pipe and the seabed varies with velocity, partly due to drainage effects. In this paper a numerical model is used to explore the effect of velocity-dependent seabed friction. A velocitydependent friction model is implemented in commercial software ABAQUS and validated via single element and simple (flat seabed) pipeline cases. This model features upper and lower friction limits, with a transition that occurs as an exponential function of velocity. A parametric study is performed using differing rates of heating and cool-down in walking situations driven by seabed slope, SCR end tension and the difference between heat up and cool down rates. The walking behaviour is compared to cases with constant friction and solutions are proposed to express the velocity-dependent response in terms of an equivalent constant friction. These equivalent friction values can then be applied in existing simple solutions or more complex numerical analyses, as a short cut method to account for velocity-dependent friction.
\end{abstract}

Key words: subsea pipelines; walking; velocity dependent seabed friction. 


\section{INTRODUCTION}

During the operational life of a seabed pipeline, it undergoes many start-up and shut down cycles leading to pipe-soil interaction forces that control the expansion and accumulated movement. Accumulated axial movement due to repeated thermal cycles may lead to global displacement, referred to as pipeline walking, and the pipeline may be designed to buckle laterally to relieve the internal loads. The axial pipe-soil interaction forces have significant influence on the design for walking and lateral buckling. Even though a significant amount of experimental data on axial friction has been available [1], the equivalent friction coefficient for structural analysis of pipeline is often selected without considering the significant effect of the pipeline velocity or history of movement [2].

In this paper an axial pipe-soil interaction model with a velocity-dependent friction coefficient is introduced. The model originates in the study of friction between solid materials. It has been established in tribology that the friction coefficient that opposes the initiation of slipping from a sticking condition is different from the friction coefficient that opposes established slipping [3-5]. The former is typically referred to as the 'static' friction coefficient, and the latter is referred to as 'kinetic' friction coefficient. Typically the static friction coefficient is higher than the kinetic friction coefficient. One model to capture this behaviour assumes that the friction coefficient rates exponentially from the static to the kinetic value according to the formula:

$$
\mu=\mu_{k}+\left(\mu_{s}-\mu_{k}\right) e^{-v a}
$$

where $\mu_{k}$ is the coefficient of kinetic friction, $\mu_{s}$ is the coefficient of static friction, $v$ is the relative velocity of the surfaces, or the slip rate, and $a$ is the rate factor [6]. When $a=0, \mu=\mu_{\mathrm{s}}$. With increasing $a$, the transition between the limiting values of friction occurs at a lower velocity as shown in Figure 1.

Recently a new analytical framework for estimating a velocity dependent friction coefficient on clay soils was developed [2] and matched with the available experimental data as:

$$
\frac{F}{W^{\prime}}=\left(\frac{F}{W^{\prime}}\right)_{\text {drained }}-\left[\left(\frac{F}{W^{\prime}}\right)_{\text {drained }}-\left(\frac{F}{W^{\prime}}\right)_{\text {undrained }}\right] e^{\ln (2)\left(\frac{T}{T_{50}}\right)^{m}}
$$

where $F$ is the frictional sliding resistance, $W^{\prime}$ is the weight of the pipe, $T$ is the time and $T_{50}$ is the time at which the frictional resistance is $50 \%$ of the undrained and drained limits. Here, the value of $T_{50}$ is close to 0.05 , and $m=0.5$. T can be calculated as $T=c_{\mathrm{v}} t / D^{2}$, where $c_{\mathrm{v}}$ is the consolidation coefficient for the soil and $D$ is the diameter of the pipe. This model captures the observed trend 
for low undrained friction to be mobilised for high speed or short duration axial pipe movements, and a high drained friction to be mobilised for long distance slower movements.

In the present analysis a similar model to those proposed in equations (1-2) has been applied to the resistance between a pipe and the seabed during axial pipeline motion. The parameter $\mu_{\mathrm{k}}$ is replaced by $\mu_{\mathrm{LB}}$, the apparent coefficient of friction in undrained conditions and $\mu_{\mathrm{s}}$ by $\mu_{\mathrm{UB}}$, the coefficient of friction in drained conditions. The form of the relationship has been kept constant, but the exponential index was recast slightly as :

$$
\mu=\mu_{L B}+\left(\mu_{U B}-\mu_{L B}\right) e^{-\lambda \frac{v}{v_{50}}}
$$

where the term $v_{50}$ is the velocity at which the friction factor lies $50 \%$ of the way between the limiting values. The velocity parameter, $v_{50}$, depends on the drainage behaviour of the soil and can be estimated from laboratory tests and varies from soil to soil. Figure 2 shows the relation between friction factor and velocity given by equation (3); this model is referred to throughout this paper as the friction rate model. The position of $v_{50}$ is indicated in the diagram. The constant $\lambda$ is equal to $\ln 2$ (0.693) because $e^{-\ln 2}=0.5$.

\section{OBJECTIVE}

The present design practice for analysing pipeline walking behaviour was discussed in the previous paper, and the conventional elastic-plastic pipe-soil response was analysed. In conventional analyses, the rate of thermal loading during operating cycles is not considered within the analysis. However, the velocity varies with position along the pipeline and with time during the startup or shutdown event. Recently, it has been recognised that the sliding resistance between a pipe and the seabed varies with velocity due to drainage effects [1,2], but to date this has not been incorporated in any structural modelling of pipeline walking.

This paper develops a numerical model in which dynamic walking behaviour is studied in detail. A velocity-dependent friction model is implemented in commercial software ABAQUS and validated via single element and simple (flat seabed) pipeline cases. This model is then used for a parametric study exploring walking driven by seabed slope and SCR end tension. The effect of differing rates of heating and cool-down on walking behaviour are also investigated. Finally, the potential to express the velocity-dependent response in terms of an equivalent friction is explored. 


\section{VELOCITY DEPENDENT PIPE-SOIL RESISTANCE}

It has been recognised that the sliding resistance between a pipe and the seabed varies depending on the velocity of movement. This is principally due to the effects of consolidation and drainage.

To establish more realistic pipe-soil interaction, time dependent pipe-soil friction model tests were performed recently [7-9]. The tests revealed that axial resistance is strongly influenced by the rate of movement and the pause period between the movement events. The higher peak values of friction factors were associated with longer waiting periods between axial sweeps and the lowest residual values were associated with the fastest rates of shearing.

\subsection{Existing data}

The effect of velocity on interface shear strength is shown in Figure 3 [8]. The response of finegrained soil during shearing varies between fully drained and fully undrained conditions across a wide range of velocities [7]. Data from previous research [8, 9] have been summarised in the figure, with $\tau_{\text {res }}$ the mean shear stress on the pipe surface curing steady motion at velocity $v$ and $\sigma_{\text {no }}^{\prime}$ the initial normal effective stress. These results are all from clay samples with an over consolidation ratio (OCR) of 1 , where the OCR is the ratio of the previous maximum effective stress to the current effective stress. A value of OCR $=1$ is typical for soft clay seabeds, particularly when disturbed and then loaded by the process of laying and then operating a pipeline. For a high velocity, partially or fully undrained conditions will prevail, and positive or negative excess pore pressure will be generated [10]. For these normally and lightly over consolidated soils, the drained friction represents an upper bound (UB) and the undrained friction represents and lower bound (LB).

This paper applies a more accurate model of the response than previous studies of pipeline walking, via a friction rate model that links these two limits.

\subsection{Representing present data with rate model}

Figure 4 represents the previous data fitted with the friction rate model. The actual data is in good agreement with the friction rate model. However, in each case the $v_{50}$ parameter was varied to fit the data for particular drained and undrained limits. The data show that, with increasing sliding rate, undrained (lower bound) friction ratio prevails. 


\section{NUMERICAL MODELLING WITH FRICTION RATE MODEL}

Numerical analyses were carried out using the quasi-static method [11] in the commercial software ABAQUS to investigate the effect of the rate model on the walking behaviour of submarine pipelines. Firstly, a benchmarking case was studied with a flat seabed and a single pipe element, where the pipe was moved back and forth with certain velocities. The friction factors were calculated from the output and were compared with the predicted outcomes. This exercise confirmed that the friction rate model was operating correctly.

Thereafter, a length of pipe was considered, where the pipe was heated-up very fast and cooled down slowly to show the operation of the rate model on a full pipeline. This was first performed for a flat seabed case, and the variation in friction along the pipe length and the consequent end expansions were examined.

The rate model was then used to show the difference in walking behaviour for various driving mechanisms. The effect of the rate model on walking due to SCR tension, seabed slope and thermal transients was studied in detail. In each case an attempt has been made to express the complex outcomes from the rate model in a simpler way by plotting the force profiles and walking rates and thereby comparing them with the response for conventional friction models based on the undrained and drained friction limits.

Finally, a parametric analysis was carried out to evaluate the walking rate for different rate models. Once the walking rate was derived from the numerical analysis, a back calculation was made to find out the equivalent velocity-independent friction factor for each of case. The aim of this step is to illustrate to what extent the velocity-dependent friction behaviour can be mimicked in a conventional analysis using a single friction coefficient.

\subsection{Non-dimensional analysis}

The results of numerical analysis were synthesised in non-dimensional manner. Various dimensionless groups were identified as follows:

\subsubsection{Relative duration of operations}

Firstly, the relative rate of heating and cooling was considered with a dimensionless time parameter, $T_{h c}$ is defined as: 


$$
T_{h c}=\frac{t_{H}}{t_{C}}
$$

where, $t_{H}$ is the time of heating and $t_{C}$ is the time of cooling. Throughout this analysis $T_{h c}$, was considered to be 0.01 unless otherwise specified. The heating of the pipe is rapid, reflecting a sudden flooding with product, whereas the cooling is slower, reflecting heat loss through conduction into the surrounding soil and water.

\subsubsection{Characteristic and Dimensionless velocity}

Another dimensionless group was formed by dividing the characteristic velocity of the pipe expansion by $v_{50}$. This group is essentially the ratio between (twice) the velocity of the ends of the pipe if the thermal expansion is unconstrained, and the characteristic velocity of the soil drainage.

The characteristic pipe velocity, $V_{p}$ is given by:

$$
V_{p}=\frac{\alpha(\Delta \theta) L}{\sqrt{t_{H} \cdot t_{C}}} \mathrm{~m} / \mathrm{s}
$$

where $\alpha$ is the coefficient of thermal expansion of the pipe material, $\Delta \theta$ is the temperature change, $L$ is the length of the pipe. In most of these analyses, values of the parameters were maintained at $\alpha=1.2 \mathrm{E}^{-06} /{ }^{\circ} \mathrm{C}, \Delta \theta=90^{\circ} \mathrm{C}, L=2000 \mathrm{~m}, t_{H}=10 \mathrm{~s}$ and $t_{C}=1000 \mathrm{~s}$. These give $V_{p}=0.00216 \mathrm{~m} / \mathrm{s}$. Although the absolute values of $t_{H}$ and $t_{C}$ are impractically small, the corresponding dimensionless velocities span the range between drained and undrained conditions for the particular values of $v_{50}$ adopted.

The dimensionless velocity is therefore:

$$
\psi=\frac{\alpha(\Delta \theta) L / \sqrt{t_{H} \cdot t_{C}}}{v_{50}}
$$

To vary $\psi$, the soil property $v_{50}$ was varied.

\subsubsection{Characteristic strain}

The characteristic strain in the pipeline, $\varepsilon_{c}$, is the ratio between the total pipe weight, $W \mathcal{L}$, which controls the force profile in the pipe through the mobilised friction coefficient, and the axial stiffness of the pipe, $E A$, thus 


$$
\varepsilon_{c}=\frac{W^{\prime} L}{E A}
$$

Through most of this paper the dimensionless strain was kept constant at 0.00072 , based on $W^{\prime}=$ $6.9 \mathrm{kN} / \mathrm{m}, L=2000 \mathrm{~m}$ and $E A=1.9 E^{+10} N$. This axial stiffness corresponds to a steel pipe of outer diameter, $D=0.912 \mathrm{~m} \mathrm{(36")}$ and wall thickness, $t=0.033 \mathrm{~m}$.

The characteristic strain is related to the mechanical strain that shortens the pipeline when the friction is full mobilised. In this case, ignoring the small central region where the limiting friction is not fully mobilised, for a constant friction coefficient $\mu$, the force at the mid-point of the pipe is $\mu W L / 2$ and the average force along the pipe is $\mu W L / 4$. The consequent strain in the pipe is $\mu \varepsilon_{\mathrm{c}} / 4$ and the overall mechanical shortening is $\mu \varepsilon_{\mathrm{c}} L / 4$, or $\mu \varepsilon_{\mathrm{c}} L / 8$ at each end relative to the centre. This mechanical shortening counteracts the 'free pipe' thermal expansion at each end that is given by $\alpha(\Delta \theta) L / 2$.

\subsection{Benchmarking case - single element test}

Figure 5 illustrates the model used for the benchmarking case with the friction rate model in ABAQUS . A single element beam model, one metre in length, was used for the pipe and a rigid surface element was used for the seabed. Gravity load was applied to settle the pipe on the seabed and then dynamic steps were used to pull the pipe with specified velocities.

Two cases $A_{10}$ and $A_{100}$ were studied with different decay factor $a=10$ and $100 \mathrm{~s} / \mathrm{m}$ resulting in values for $v_{50}=0.069 \mathrm{~m} / \mathrm{s}$ and $0.0069 \mathrm{~m} / \mathrm{s}$ respectively, together with mobilisation displacement for the elastic-plastic response of the pipe-seabed interface of $u_{\mathrm{ult}}=0.01 \mathrm{~m}$. The mobilised friction factor, $\mu$ was extracted from the results of the analyses as $\mu=\tau / \sigma^{\prime}$, where $\tau$ is the shear stress in the axial direction and $\sigma^{\prime}$ is the normal pressure on the seabed. The numerical results were then compared with the theoretical model response. A pipe with diameter, $D=0.912 \mathrm{~m}$ (36") with $D / t$ $=25$ and axial stiffness, $E A=19100 \mathrm{MN}$ was used for this analysis. A yield stress, $\sigma_{\mathrm{y}}=410 \mathrm{MPa}$ was also specified for the pipe element, but the yield stress was not reached in this analysis and the pipe remained elastic throughout.

For the soil, throughout this study, an undrained friction factor, representing a lower bound (LB), of $\mu_{\mathrm{UD}}=0.1$ was adopted, along with a drained friction factor, representing an upper bound (UB) of $\mu_{\mathrm{D}}=0.6$. The input velocities and the rate (and rate, $v_{50}$ ) factors were tabulated in Table 1 . The velocity was slowly ramped up to $10 \mathrm{~m} / \mathrm{s}$ and then reduced by a factor of 10 in six steps to 
$0.00001 \mathrm{~m} / \mathrm{s}$ and then again increased back to $10 \mathrm{~m} / \mathrm{s}$ for both cases. Every time step was of equal duration (10 s) for simplicity. Figure 6 shows the resulting velocity regime.

Figure 7 shows the comparison between analytical model and the numerical results. The velocity was varied from a very high value of $10 \mathrm{~m} / \mathrm{s}$ to a low value of $0.00001 \mathrm{~m} / \mathrm{s}$ and then again increased from the low value to the high value. By doing this a wide range of velocities were covered in order to judge the accuracy of the friction rate model. The calculated equivalent friction factor matches closely with the theoretical expression, confirming correct operation of the model.

\subsection{Benchmarking case $-2 \mathrm{~km}$ pipeline on flat seabed $(\beta=0)$}

For the second benchmarking case the same input parameters were chosen for a $2 \mathrm{~km}$ long pipeline resting on a flat seabed. The pipe is assumed to have free ends, therefore, a boundary condition of zero force applies.

The times of heating and cooling were varied to investigate the effect of velocity and the resulting velocity dependent friction on the end expansion of the pipeline. For this analysis the dimensionless time $T_{h c}$ was maintained at 0.01 , with the time of heating taken as $t_{\mathrm{H}}=10 \mathrm{~s}$, and hence the time of cooling was $t_{\mathrm{C}}=1000 \mathrm{~s}$, with 5 full cycles simulated starting with heating by $90^{\circ}$ and then cooling by the same amount. A waiting time of $t_{\text {wait }}=100 \mathrm{~s}$ was introduced following each heating or cooling stage to stabilise the unbalanced forces present at the end of the very fast heating. For these input parameters and taking $v_{50}$ as $0.0693 \mathrm{~m} / \mathrm{s}$, the dimensionless velocity is $\psi$ $=0.0311$.

The dimensionless characteristic strain parameter, $\varepsilon_{c}$ was kept constant at 0.00072 . Cases using the drained (UB) and undrained (LB) friction factors as well as the rate model were used. The results of all of these models are compared in the following sections. Two key outputs are the end movements and the mobilised friction at the free ends of the pipeline which are plotted against time. In addition, the force envelopes and the mobilised friction along the length of the pipeline at the end of each change in temperature are also compared.

Figure 8 shows the end displacement of the pipe at $x=0$ over the five heating and cooling cycles for different friction models, reflecting the net expansion of the pipeline. Firstly the end displacements are plotted for both drained and undrained friction factors. The drained friction factor leads to smaller expansion of the pipe and a lower cyclic range, reflecting the greater mechanical compression in response to the expansive thermal strains, and the greater mechanical 
extension in response to the contraction. After the first expansion the cyclic response repeats exactly.

The end expansion in response to the rate model is superimposed on the plot. The response matches the drained solution during cool down - when the velocity is slow, and the mobilised friction is close to the drained - and matches the undrained solution at heat up step - when the velocity is fast. These effects are also evident in the effective friction at the end of the pipe, which is shown in Figure 9.

Figure 10 shows the comparison of force profiles between the drained, undrained and rate models and Figure 11 shows the corresponding variation in mobilized friction along the pipe. The friction profile was calculated by dividing the change in force along the length $d P / d x$, by the unit weight of the pipe, $W^{\prime}$.

These results show that during the slow cool down process the mobilised friction along the entire length of the pipeline is similar to the drained value, resulting in an almost linear variation in force. However, the more rapid heat up process causes velocities in the range over which the friction varies significantly. The result is a non-linear variation in force along the pipe. The profile matches the undrained friction case near the fast-moving pipe ends, but the mobilised friction is higher near the center of the pipe, where the velocity is lower.

Figure 12 shows an enlarged view of the central portion of the pipe during cool down steps. The drained (UB), undrained (LB) and rate model created a zig-zag portion at the center of the pipe. These are due to the presence of mobilisation displacement in the elastic-plastic pipe-seabed frictional interface model used in ABAQUS. During cooling down and heating up the pipe experiences inward and outward displacements of the pipe respectively. However, because of the previous heating cycle, the cooling stage does not give sufficient inward displacement near the center of the pipe to reverse the sense of the friction.

\subsection{Walking due to SCR tension}

A comparative study is presented in this section to investigate the effect of the rate model on steel catenary riser (SCR) tension. The force profiles, mobilised friction (expressed as the ratio of change in force along the length to the weight of the pipe) and walking rates were compared between velocity independent and velocity-dependent friction for particular non-dimensionalised terms $\psi=0.0311, T_{\mathrm{hc}}=0.01$ and $\varepsilon_{\mathrm{c}}=0.00072$. For this case SCR tension of $500 \mathrm{kN}$ at $x=0$ was considered, maintaining a free end at $x=2000 \mathrm{~m}$. 


\subsubsection{Force profile}

Figure 13 shows the comparison of force envelopes for drained (UB), undrained (LB) and rate friction models. The force profiles of the drained and rate models at the cool down step are comparable. However, the maximum force reached with the rate model is slightly lower than the drained value. This was due to the selection of total time for the cool down step. The maximum value reached with the rate model in the heating step was higher than the undrained value. However, the slopes of the undrained and rate models match very closely towards the free end of the pipe.

\subsubsection{Friction profile}

Friction profiles are plotted in Figure 14. Mobilised friction was calculated from the force profile as previously by $(d P / d x) / W^{\prime}$. The drained (UB) and undrained (LB) values were 0.6 and 0.1 respectively and the resulting force profiles are shown by the solid lines. However, the results of the rate model match closely with the drained response over most of the pipe length for the cool down step but with the undrained response towards each end of the pipe for the heating step.

\subsubsection{Walking rate}

The walking rate over the five cycles is compared for the drained (UB), undrained (LB) and rate model in Figure 15. For the first cycle the walk rate was similar for all the friction. However, the effects of friction factors were more prominent after the second cycles due to the stabilisation of the model from the second step onwards. The walking rate with the undrained friction was much higher than for the drained case while results for the rate model fall in between the drained and undrained responses.

\subsection{Walking due to seabed slope}

A comparative study is presented in this section to investigate the effect of the rate model on seabed slope with an angle $\Phi$. Similar to previous section force profiles, mobilised friction and walking rates were compared for drained, undrained and rate models keeping $\psi=0.0311, T_{\mathrm{hc}}=$ 0.01 and $\varepsilon_{\mathrm{C}}=0.00072$. For this case a seabed slope angle of $\Phi=3^{\circ}$ was considered, with the lower end at $x=0$.

\subsubsection{Force profile}

Force profiles for drained (UB), undrained (LB) and rate models are compared in Figure 16 for the seabed slope case. The maximum force reached with the rate model during cool down is slightly lower than for the drained case. The maximum compressive force reached with the rate 
model in the heating step was higher than for the undrained case. However, the slopes for the drained and rate models match closely towards the free end of the pipe.

\subsubsection{Friction profile}

Figure 17 compares friction profiles (strictly ratios of force gradient to pipe weight) for the drained (UB), undrained (LB) and rate models with a seabed slope. The friction values for drained $(\mu=0.6)$ and undrained $(\mu=0.1$ ) respectively are shown by the solid lines and corresponding results for the rate model by dashed lines. Results of the rate model match closely with the drained case over most of the pipe length, especially over the central part, for the cool down step but more closely with the undrained case towards each free end for the heating step.

\subsubsection{Walking rate}

Similar to the previous case of SCR tension, the walking rate over the five cycles is compared for drained (UB), undrained (LB) and rate models in Figure 18. For the first cycle the walk rate was similar for all the friction models. However, the effects of friction factors became more prominent during subsequent cycles due to stabilisation of the model from the second step onwards. The walking rate with the undrained (LB) friction was much higher than for the drained case while results for the rate model falls between the drained and undrained responses.

\subsection{Walking due to thermal transients}

A comparative study has been carried out in this section to investigate the effect of the rate model on walking triggered by thermal transients. For this case the pipe is assumed to have a constant initial temperature of $10^{\circ} \mathrm{C}$ initially, and at the end of each cool down. However, during heating a constant temperature gradient of $10^{\circ} \mathrm{C} / \mathrm{km}$ (hottest at $x=0$ ) is assumed. The same dimensionless parameters of $\psi=0.0311, T_{\mathrm{hc}}=0.01$ and $\varepsilon_{\mathrm{c}}=0.00072$ were adopted.

\subsubsection{Walking rate}

Figure 19 shows the comparison of walking rate for drained (UB), undrained (LB) and rate models for the thermal transient case. The walking rates over five cycles are presented for the cold end of the pipe $(x=2000 \mathrm{~m})$. The dotted line represents the displacements with the rate model, whereas the solid lines represent the drained and undrained friction cases. The walking rate with undrained friction was higher than for drained friction and that with the rate model falls between these cases. 


\subsubsection{Force profile}

The force profiles with the rate model are shown in Figure 20 for the thermal transient case with the rate model. Force envelopes from the second heat up and cool down cycles till the fifth cycle are plotted, and show that the force profile stabilized after the second cycle.

\subsection{Distributed displacements with rate model}

The distributed displacement at various locations along the pipe are presented here to illustrate the total walking behaviour of the pipeline with the rate model, for the cases of an applied SCR tension, a seabed slope and thermal transients.

\subsubsection{SCR tension}

Figure 21 shows the axial displacement at various points along the length of the pipeline, for the case of SCR tension of $500 \mathrm{kN}$ applied at $x=0$. Other results for this case have been presented previously. Towards each end of the pipeline the displacements cycle between outward during heating and inward during cooling. However, there is a net cumulative (negative) displacement towards the applied SCR tension. This is most evident at the centre of the pipeline where the displacements are negative during both heating and cool down steps

\subsubsection{Seabed slope}

Figure 22 shows the plot of axial movement along the length of the pipe with a seabed slope, $\beta=$ $3^{\circ}$ as indicated in the plot. The pattern of displacements is very similar to that for the SCR tension case, but with larger net downhill (negative) cumulative displacements. During each heating and cool down step the displacements at the pipeline centre are negative and even at $x=1500 \mathrm{~m}$ the net heating displacements become slightly negative after the first cycle.

\subsubsection{Thermal transients}

Figure 23 shows the cyclic displacements along the length of the pipe for a thermal transient of $10^{\circ} \mathrm{C} / \mathrm{km}$, as indicated in the plot. The cyclic displacements follow a similar pattern to those with no thermal gradient, being outward from the pipeline centre during heating, and inward during cool down. The main difference relative to the previous two cases is there is much less net walking of the pipeline. At the centre, $x=1000 \mathrm{~m}$, small cyclic displacements occur due to the additional heating for $x<1000 \mathrm{~m}$ compared with $x>1000 \mathrm{~m}$, but with barely discernible accumulation over successive cycles. 


\section{PARAMETRIC STUDY EXPLORING EQUIVALENT FRICTION}

A parametric study was carried out to investigate the effect of dimensionless velocity on the walking rate of the pipeline, to establish an approach to define an equivalent single value of friction when using the rate model. Input parameters are tabulated in Table 2. The midpoint velocity of the friction rate model was varied from $v_{50}$ of $0.0069 \mathrm{~m} / \mathrm{s}$ to $69.31 \mathrm{~m} / \mathrm{s}$ (see Figure 24). This range allowed simulations to cover both extremes of the friction model. Non-dimensional parameters $\psi$ and $\varepsilon_{\mathrm{c}}$ (which was kept constant) are shown in Table 3. All three pipeline walking mechanisms were studied in the following section to understand how the walking rate is affected by the velocity parameter, and how a simple equivalent value might be selected in practice.

\subsection{SCR tension}

Figure 25 depicts the effect of SCR tension and dimensionless velocity on the walking rate. The SCR tension was varied from 100 to $500 \mathrm{kN}$ and the dimensionless velocity was varied from 0.00312 to 31.2. The portions of the walking profile affected by drained and undrained friction behaviour are indicated. The walking rate became essentially constant below the velocity limit ( $\psi \sim 0.1$ ) controlled by drained friction. The walking rate increased with increasing normalized velocity $\psi$ and reached a plateau with constant walking rate controlled by undrained friction for $\psi>5$.

\subsection{Seabed slope}

Figure 26 shows the effect of seabed slope and dimensionless velocity on the walking rate. The slope $\beta$ was varied from $1^{\circ}$ to $3^{\circ}$ and the normalized velocity was varied from $6.83 \mathrm{E}^{-05}$ to 0.683 . Arrows show the portions of the waking profile dictated by drained and undrained friction. Similar to the previous case the walking rate was constant below the undrained velocity limit of $\psi \sim 0.1$ and then increased to a value beyond which the walking rate was controlled by drained friction and constant for $\psi>5$.

\subsection{Thermal transients}

Figure 27 depicts the effect of thermal transients and dimensionless velocity on the walking rate. The thermal transients were varied from 10 to $30{ }^{\circ} \mathrm{C} / \mathrm{km}$ and the normalized velocity was varied from $6.83 \mathrm{E}^{-05}$ to 0.683 . The portions of the walking profile affected by the drained and undrained frictions are indicated, with the walking rate constant below the drained velocity limit of $\psi \sim 0.1$ and $\psi>5$. As noted previously with reference to Figure 23, the walking rate due to thermal transients is significantly lower than for typical SRC tension or seabed gradients.. 


\subsection{Equivalent friction factor}

Sets of data have been generated in the previous section which shows the relation between the velocities of pipeline to the walking rate. However, for the design engineers a simple static friction representing the walk per cycle affected by the dimensionless velocity would be beneficial. Therefore, back calculations were made based on the existing analytical models [12] to derive the equivalent friction factor for each of the walk rate. The representative equivalent friction factor was then plotted against the dimensionless velocity and a fit proposed to estimate the equivalent friction factor.

The equivalent friction was fitted via an exponential rate model, matching the underlying rate model for the friction applied at each element within the simulations. Figure 28 depicts the representative friction factor matched closely with the back calculated friction factors from walking rate. For SCR tension case the expression of equivalent friction can be given by:

$$
\mu_{e q}=\mu_{L B}+\left(\mu_{U B}-\mu_{L B}\right) e^{-0.95 \psi}
$$

Similarly, the equivalent friction factor for seabed slope (in Figure 29) can be evaluated as:

$$
\mu_{e q}=\mu_{L B}+\left(\mu_{U B}-\mu_{L B}\right) e^{-0.95 \psi}
$$

The proposed models are in good agreement with the numerical results. Therefore, the equivalent friction factors can be used to simulate the walking behaviour of pipelines subjected to different thermal cycles during operation, knowing the dimensionless velocity of the pipe (Equation 5). This parameter can be determined a priori, without performing any analyses, since it is related only to the free pipeline expansion, the duration of the change in temperature and the friction model parameter, $v_{50}$.

\subsection{Effect of time ratio $T_{\text {hc }}$}

Until now the dimensionless time - being the ratio between heat-up and cool-down duration, $T_{\mathrm{hc}}=t_{\mathrm{H}} / t_{\mathrm{C}}-$ was kept constant at 0.01 . However, here the effect of $T_{\mathrm{hc}}$ is investigated, varying it in the range $1000-0.001$, by varying the heating time, $t_{\mathrm{H}}$ and keeping the cooling time $t_{\mathrm{C}}$ constant at 1000 seconds. For these analyses the seabed slope, $\beta$ was kept constant at $3^{\circ}$, and effective characteristic strain, $\varepsilon_{\mathrm{c}}$ at 0.00072 as before.

Similar to previous cases equivalent friction factor was back calculated from the walking rate for each case and compared with the proposed equivalent friction model. Figure 30 depicts the fitting 
of the proposed model for different dimensionless times, $T_{\mathrm{hc}}$ for a constant $\varepsilon_{c}$ and $\beta$. The proposed model shows good agreement with the results of individual analyses. A direct comparison of the proposed data and analysis results across the range of $\psi$ values is shown in Figure 31, again showing close agreement.

The force profiles for various cases $\left(T_{\mathrm{hc}}=1000-0.001\right)$ are shown in Figure 32. The walking rate decreases with increasing $T_{\mathrm{hc}}$, as may be inferred from the gradually increasing offset of the maximum axial force from the pipeline centre as $T_{\mathrm{hc}}$ decreases.

\subsection{Effect of characteristic strain, $\varepsilon_{c}$}

The characteristic strain, $\varepsilon_{c}$ expresses the ratio of the total pipeline weight divided by the axial stiffness of the pipe. Hence if the weight of the pipe changes proportionally with axial stiffness (essentially the cross-sectional area) of the pipe, $\varepsilon_{c}$ does not change and the walking rate is not affected. However, for a particular size of the pipe, if the weight of the pipe is increased the walking rate is reduced. Figure 33 shows the effect of the characteristic strain on the walking rate of a pipe on sloping seabeds. Two different seabed slopes of, $\beta=1^{\circ}$ and $3^{\circ}$ were considered for three different pipe sizes of $D=0.152 \mathrm{~m}, 0.304 \mathrm{~m}$ and $0.912 \mathrm{~m}$. The pipe length, $L$ was kept constant at $2000 \mathrm{~m}$. The dimensionless speed, $\psi$ was kept constant at 0.0311 and the dimensionless time, $T_{\text {hc }}$ was kept constant at 0.01 .

It was confirmed that, for a given value of $\varepsilon_{c}$, but for pipes with different diameter and thickness, the walking rate is the same for a particular seabed slope. However, when the weight of the pipe was doubled or halved by keeping all other parameters constant and for a particular diameter, the walking rate was reduced and increased respectively. This phenomenon was observed for both values of seabed slope.

\section{CONCLUSIONS}

High temperature and high pressure seabed pipelines are often subjected to cyclic expansion during their operating cycles. These repeated thermal cycles lead to global axial displacement that is referred to as pipeline walking. To more accurately simulate the axial friction between a walking pipeline and the seabed, a velocity-dependent friction model was introduced here. Numerical analyses were carried out to investigate the effect of velocity-dependent friction on the walking behaviour of an on-bottom pipeline. The velocity dependent friction model features a 
transition between friction limits that represent very slow and very fast movements, and was first compared with existing experimental data of clay-pipe friction. Then the model was introduced into ABAQUS and was validated with the single element and then flat seabed cases. Thereafter, walking due to SCR tension, seabed slope and thermal transients were analysed and compared with models using constant friction.

Parametric results revealed the relationship between the velocity of the pipeline and the walking rate. If the pipeline movements are sufficiently fast or sufficiently slow, then the walking response matches a velocity-independent friction model tied to the lower and upper friction limits respectively. However, there is a transitional zone in which the pipeline movements mobilise a friction that lies between the two limits. The mobilized friction also varies along the length of the pipeline due to the varying expansion rate at different positions - with the ends of the pipeline always expanding or contracting the fastest. A dimensionless velocity ratio has been defined, linking the free pipeline expansion rate to the velocity at which the friction transition occurs.

For design practice, it is desirable to retain the simplicity of a simple single friction value that can be used in structural modelling or existing analytical solutions for walking rate. Therefore, back calculations were made based on the existing analytical models to derive the equivalent friction factor that matches the walking rate observed in all of the velocity-dependent friction cases. A relationship was then derived to calculate this representative equivalent friction factor based on the dimensionless velocity ratio. This model provides good agreement with the numerical results.

This analysis therefore assists in accounting for velocity-dependent axial pipeline friction in the analysis of pipeline walking. It provides a basis for converting a velocity-dependent friction response into a single equivalent friction factor, allowing for the expected expansion velocity of the pipeline. This equivalent friction can be determined a priori, without performing any numerical analyses, since it is related only to the free pipeline expansion, the duration of the change in temperature and the friction model parameter, $v_{50}$.

\section{Acknowledgements}

The research presented here forms part of the activities of the Centre for Offshore Foundation Systems (COFS), currently supported as a node of the Australian Research Council Centre of Excellence for Geotechnical Science and Engineering (grant CE110001009) and through the 
Fugro Chair in Geotechnics, the Lloyd's Register Foundation Chair and Centre of Excellence in Offshore Foundations and the Shell EMI Chair in Offshore Engineering. 


\section{References}

[1] White, D. J., Ganesan, S. A., Bolton, M. D., Bruton, D. A. S., Ballard, J-C., \& Longford, T. 2011. SAFEBUCK JIP -Observations of axial pipe-soil interaction from testing on soft natural clays. Proc of Offshore Technology Conference, Houston, USA, OTC 21249.

[2] Randolph, M. F., White, D. J., \& Yan, Y. (2012). Modelling the axial soil resistance on deepwater pipelines. Géotechnique. 62. 837-846. 10.1680/geot.12.OG.010.

[3] Rabinowicz, E. ( 1965). Friction and wear of materials. Wiley, New York:

[4] Moore, D. F. (1975). The principles and applications of tribology. Pergamon Press, Oxford.

[5] Bhushan. B. (1999). The principles and applications of tribology. John Wiley \& Sons.

[6] Oden, J. T., \& Martins. J. A. C. (1985). Models and Computational Methods for Dynamic

Friction Phenomena. Computer Methods in Applied Mechanics and Engineering, vol. 52, pp. 527-634.

[7] White, D. J., \& Cathie, D. N. (2010). Geotechnics for Subsea pipelines. Proc. of 2nd Int. Symposium on Frontiers in Offshore Geotechnics, Perth, Australia. 87-123

[8] Hill, A.J., White, D. J., Bruton, D.A.S., Langford, T., Meyer, V., Jewell, R., \& Ballard, J-C. (2012). New datasets and improved practice for assessment of axial pipe-soil interaction. Proc. SUT Conference on Offshore Site Investigation and Geotechnics, London

[9] Steelfelt, J. S. (1993). Sliding resistance for foundations on clay till. Proc. Wroth Memorial Conference, Predictive Soil Mechanics. Thomas Telford. 664-684.

[10] White, D. J., Campbell M., Boylan. N., \& Bransby, M. F. (2012). Theoretical analysis of axial pipe-soil interaction. Proc. SUT Conf on Offshore Site Investigation and Geotechnics, London.

[11] Carneiro, D., Rathbone, A., Siong, Soon, Kok., \& Viecelli, G. (2017). Velocity-Dependent Soil Resistance in Finite Element Analysis of Pipeline Walking. Journal of Offshore Mechanics and Arctic Engineering. 139. 021701-1 . 10.1115/1.4034695.

[12] Carr, M., Sinclair, F., \& Bruton, D. (2006). Pipeline Walking - Understanding the filed layout challenges, and analytical solutions developed for the SAFEBUCK JIP. Proc. of Offshore Technology Conference, Houston, USA, OTC 17945. 
Table 1: Input data range for benchmarking case:

\begin{tabular}{|c|c|c|c|c|}
\hline Cases & $\begin{array}{c}\text { Velocity, } v \\
(\mathrm{~m} / \mathrm{s})\end{array}$ & $\begin{array}{c}\text { Time, } t \\
\text { (s) }\end{array}$ & $\begin{array}{c}a \\
(s / m)\end{array}$ & $\begin{array}{c}v_{50} \\
(\mathrm{~m} / \mathrm{s})\end{array}$ \\
\hline \multirow{13}{*}{$\mathbf{A}_{10}, \mathbf{A}_{100}$} & 10 & 10 & \multirow{13}{*}{10,100} & \multirow{13}{*}{$0.069,0.0069$} \\
\hline & 1 & 10 & & \\
\hline & 0.1 & 10 & & \\
\hline & 0.01 & 10 & & \\
\hline & 0.001 & 10 & & \\
\hline & 0.0001 & 10 & & \\
\hline & 0.00001 & 10 & & \\
\hline & 0.0001 & 10 & & \\
\hline & 0.001 & 10 & & \\
\hline & 0.01 & 10 & & \\
\hline & 0.1 & 10 & & \\
\hline & 1 & 10 & & \\
\hline & 10 & 10 & & \\
\hline
\end{tabular}

Table 2: Input data range for parametric study

\begin{tabular}{lcc}
\hline Parameters & Value & Units \\
\hline Diameter, $D$ & 0.912 & $\mathrm{~m}$ \\
Length of pipe, $L$ & 2000 & $\mathrm{~m}$ \\
Cross-sectional stiffness of pipe, $E A$ & $1.9 \mathrm{E}+10$ & $\mathrm{~N}$ \\
Co-efficient of thermal expansion of pipe material, $\alpha$ & $1.2 \mathrm{E}-06$ & $/{ }^{\circ} \mathrm{C}$ \\
Change in temperature, $\Delta \theta$ & 90 & ${ }^{\circ} \mathrm{C}$ \\
Unit weight of the pipe, $W^{\prime}$ & 6.9 & $\mathrm{kN} / \mathrm{m}$ \\
Time of heat up, $t_{H}$ & 10 & $\mathrm{~s}$ \\
Time of cool down, $t_{C}$ & 1000 & $\mathrm{~s}$ \\
Midpoint velocity range of the friction model, $v_{50}$ & $0.0069-69.3$ & $\mathrm{~m} / \mathrm{s}$ \\
SCR tension, $T_{S C R}$ & $100-500$ & $\mathrm{kN}$ \\
Seabed slope, $\beta$ & $1-3$ & $10-30$ \\
Thermal transients, $q$ & & ${ }^{\circ}(\mathrm{angle})$ \\
\hline
\end{tabular}


Table 3: Non-dimensional parameters

\section{Parameters}

Characteristic velocity, $\psi$

Characteristic strain, $\varepsilon_{c}$
Value

0.000009-9.85

0.00072 


\section{Figures:}

Figure 1: Sketch showing influence of $a$ on friction factor............................................. 24

Figure 2: Nomenclature of velocity-dependent friction model ....................................... 24

Figure 3: Published data showing effect of velocity on interface shear strength (White et al.

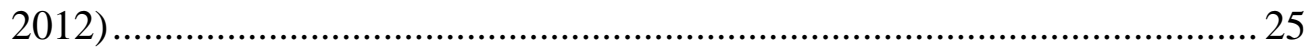

Figure 4: Fitting between data and friction rate model ................................................ 25

Figure 5: Benchmarking rate model with single element test on flat seabed..................... 26

Figure 6: Comparing velocities for single element test............................................... 26

Figure 7: Comparing analytical and numerical results for single element test .................. 26

Figure 8: End displacement for drained, undrained and rate models for flat seabed ......... 27

Figure 9: Mobilised friction at $\mathrm{x}=0$ for drained, undrained and rate models for flat

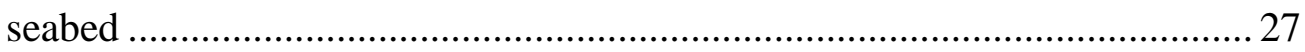

Figure 10: Force profiles for drained (UB), undrained (LB) and rate models fo............... 28

Figure 11: Friction profiles for drained (UB), undrained (LB) and rate model ................. 28

Figure 12: Enlarged view of central portion of friction profiles for ................................ 29

Figure 13: Force profiles for drained (UB), undrained (LB) and rate models with $T_{S C R}=$

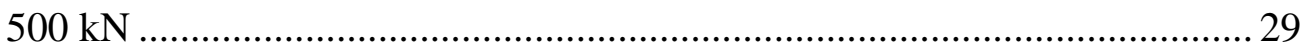

Figure 14: Friction profiles for drained (UB), undrained (LB) and rate models with $T_{S C R}=$

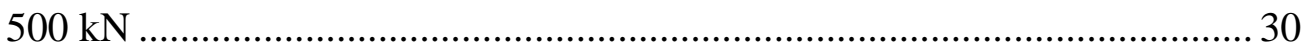

Figure 15: Walking rates for drained (UB), undrained (LB) and rate models with $T_{S C R}=$

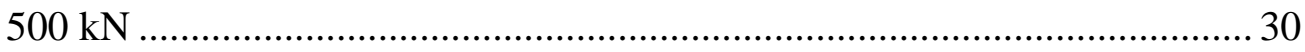

Figure 16: Force profiles for drained (UB), undrained (LB) and rate models for sloping

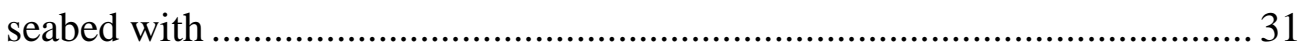

Figure 17: Friction profiles drained (UB), undrained (LB) and rate models for sloping

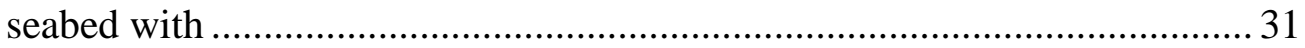

Figure 18: Walking rates drained (UB), undrained (LB) and rate models for sloping seabed with..... 32

Figure 19: Walking rates for drained (UB), undrained (LB) and rate models ................... 32

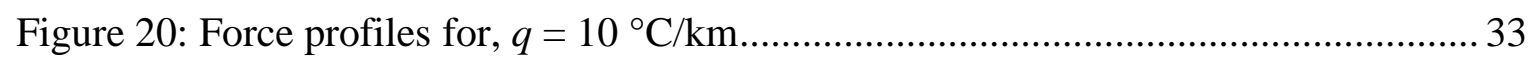

Figure 21: Distributed displacements with rate model for SCR tension, $T_{S C R}=500 \mathrm{kN}$.. 33

Figure 22: Distributed displacements with rate model for seabed slope, $\varnothing=3^{\circ} \ldots \ldots \ldots \ldots . . . . . .34$ 
Figure 23: Distributed displacements with rate model for thermal transient, $q=10$

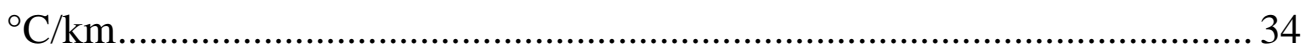

Figure 24: Range of friction models used for numerical parametric study ......................... 35

Figure 25: Effect of dimensionless velocity on walking rate for SCR tension .................. 35

Figure 26: Effect of dimensionless velocity on walking rate for seabed slope................... 36

Figure 27: Effect of dimensionless velocity on walking rate for thermal transients.......... 36

Figure 28: Equivalent friction model for SCR tension cases .......................................... 37

Figure 29: Equivalent friction model for sloping seabed cases .................................... 37

Figure 30: Comparison between proposed and calculated friction factors for varying $T_{\mathrm{hc}} 38$

Figure 31: Equivalent friction model for cases with varying ratios of heating and cooling times, $T_{\mathrm{hc}}$ 38

Figure 32: Comparison of force profiles for various ratios of heating and cooling times, $T_{\mathrm{hc}}$ 39

Figure 33: Effect of characteristic strain on walking rate of pipe for various weights ...... 39 


\section{Figures:}

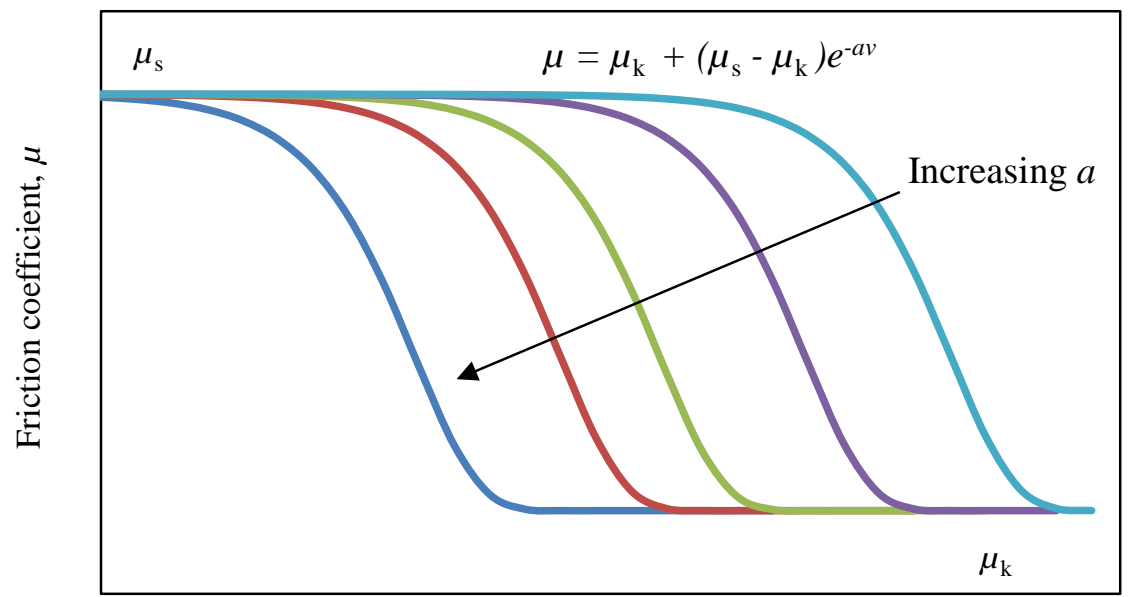

Velovity, $v(\mathrm{~m} / \mathrm{s})$

Figure 1: Sketch showing influence of $a$ on friction factor

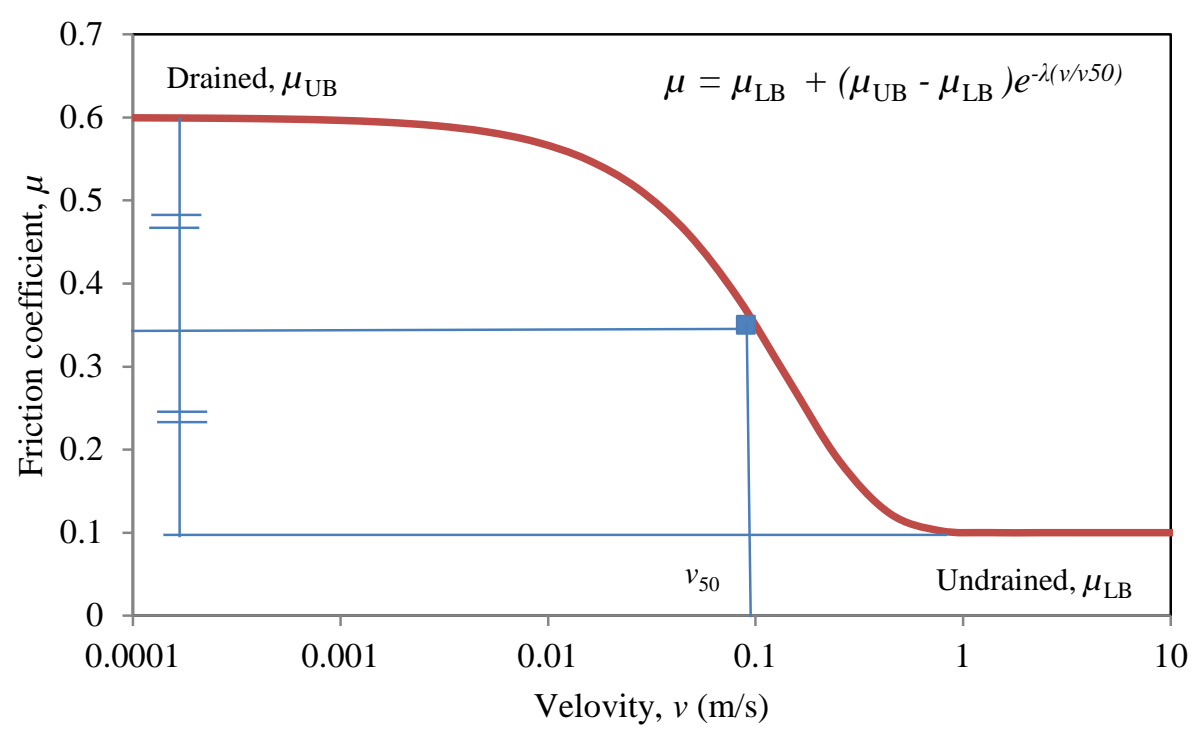

Figure 2: Nomenclature of velocity-dependent friction model 


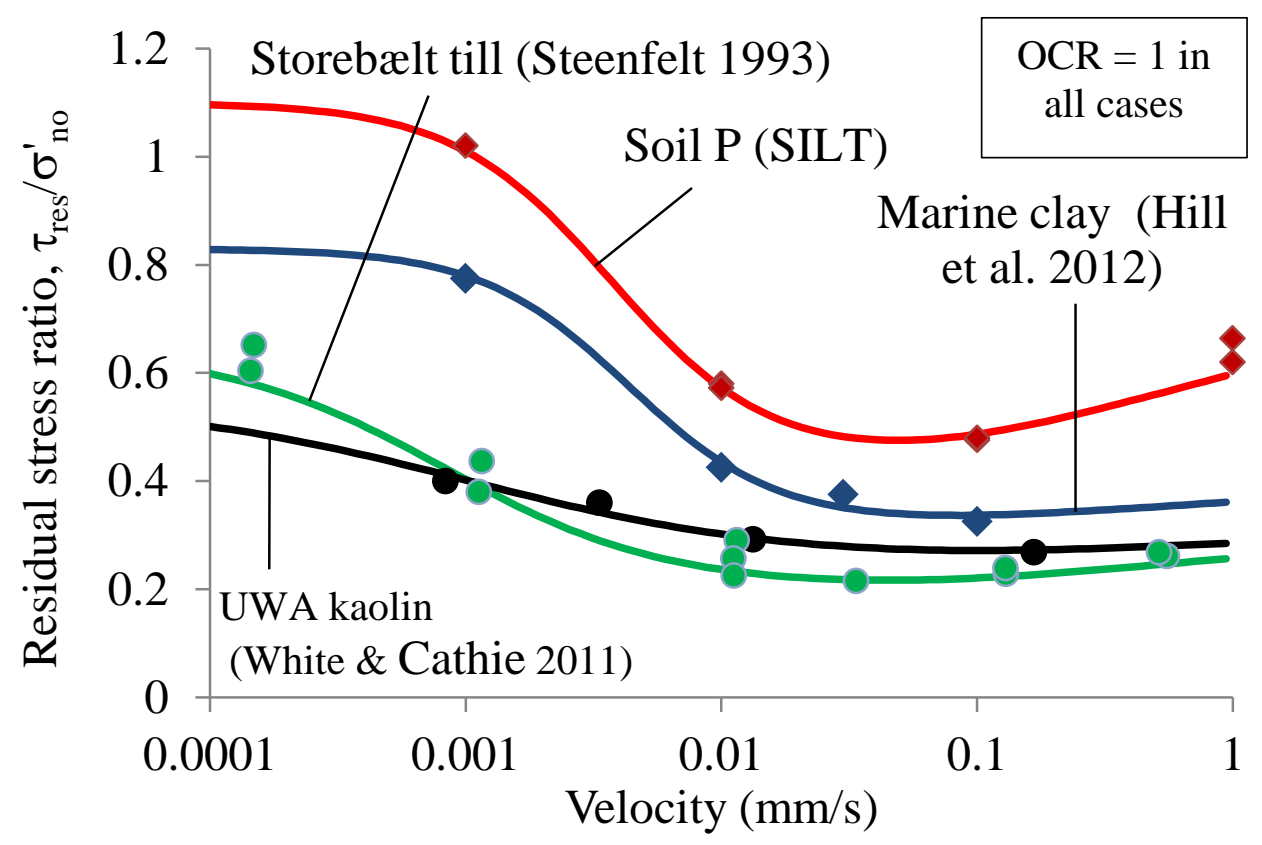

Figure 3: Published data showing effect of velocity on interface shear strength (White et al. 2012)

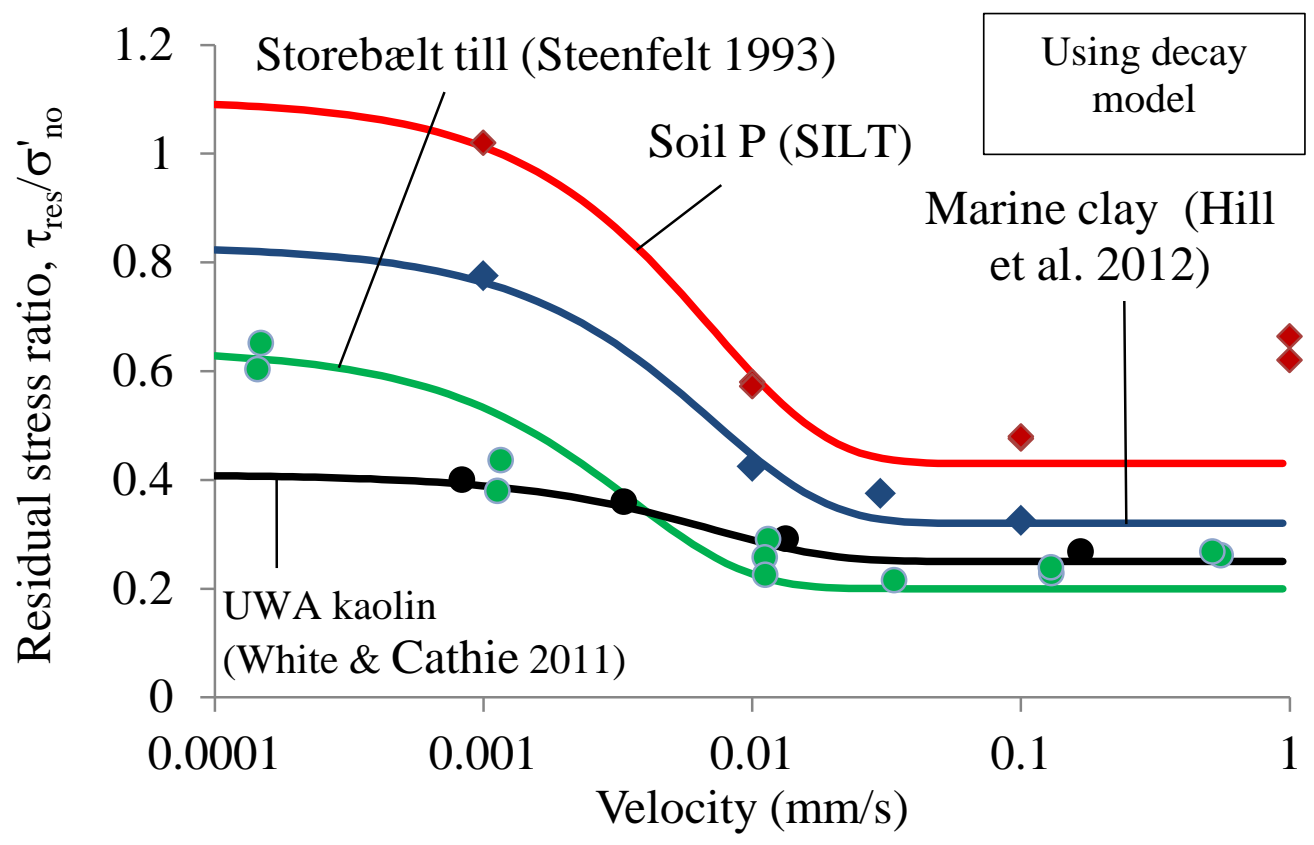

Figure 4: Fitting between data and friction rate model 


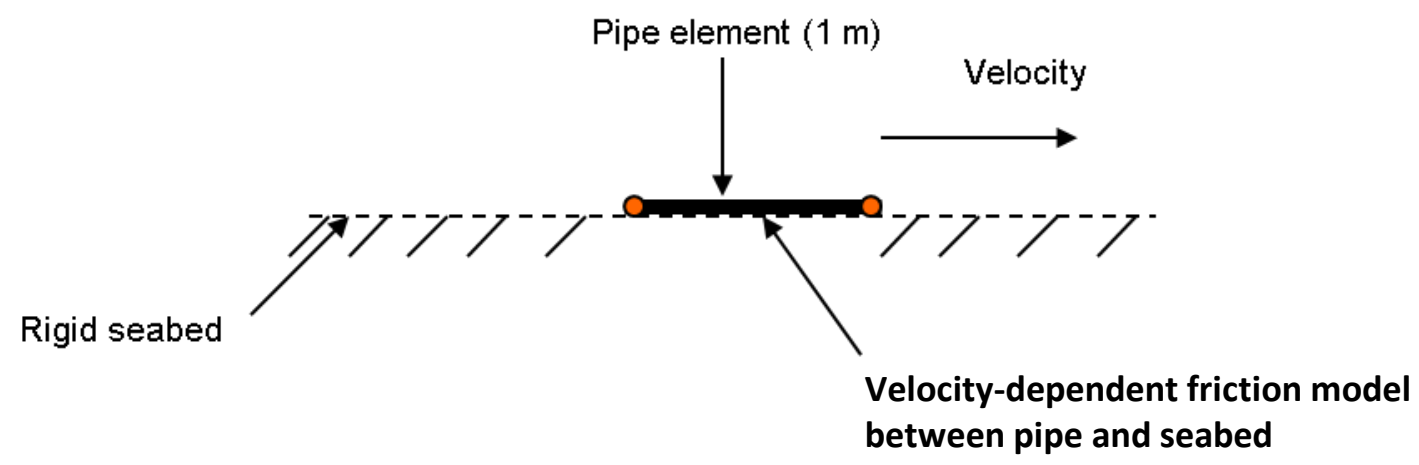

Figure 5: Benchmarking rate model with single element test on flat seabed

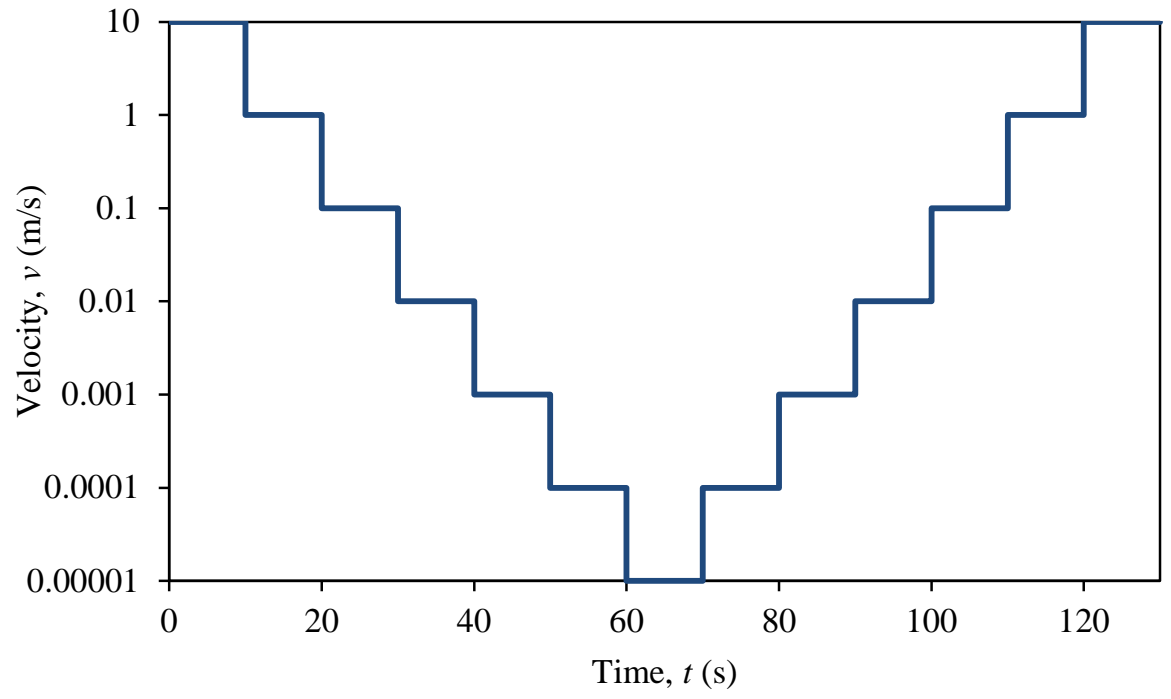

Figure 6: Comparing velocities for single element test

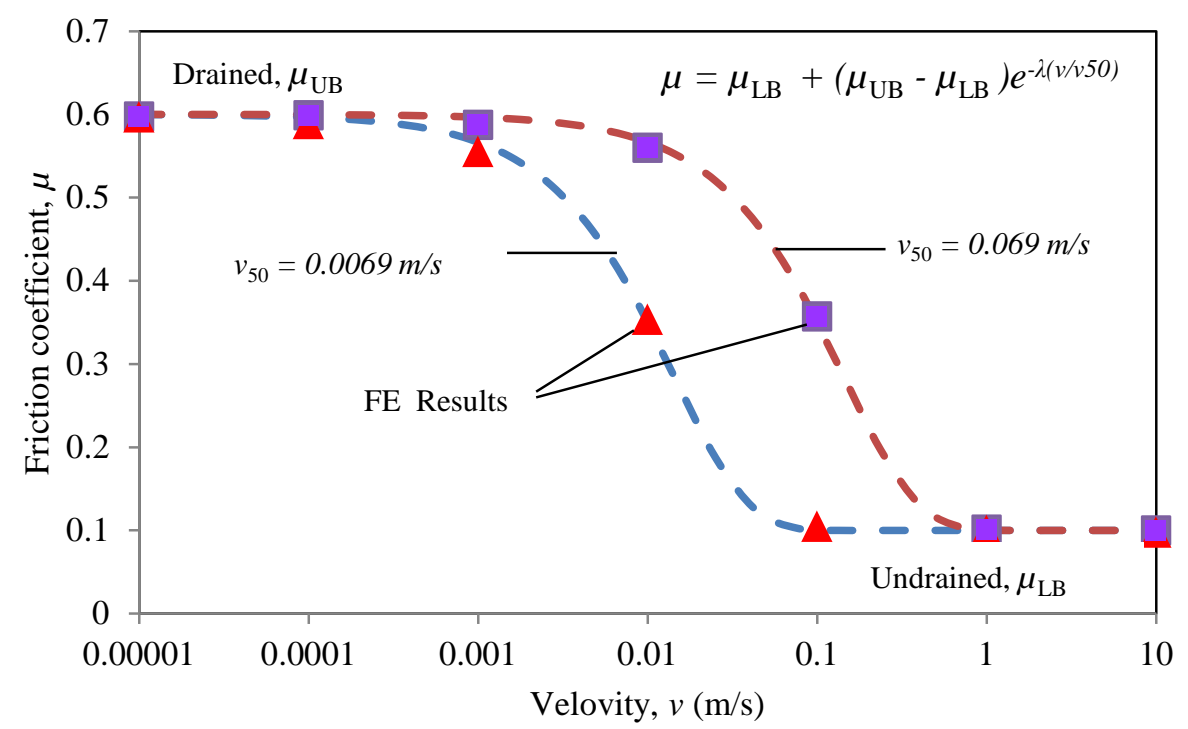

Figure 7: Comparing analytical and numerical results for single element test 


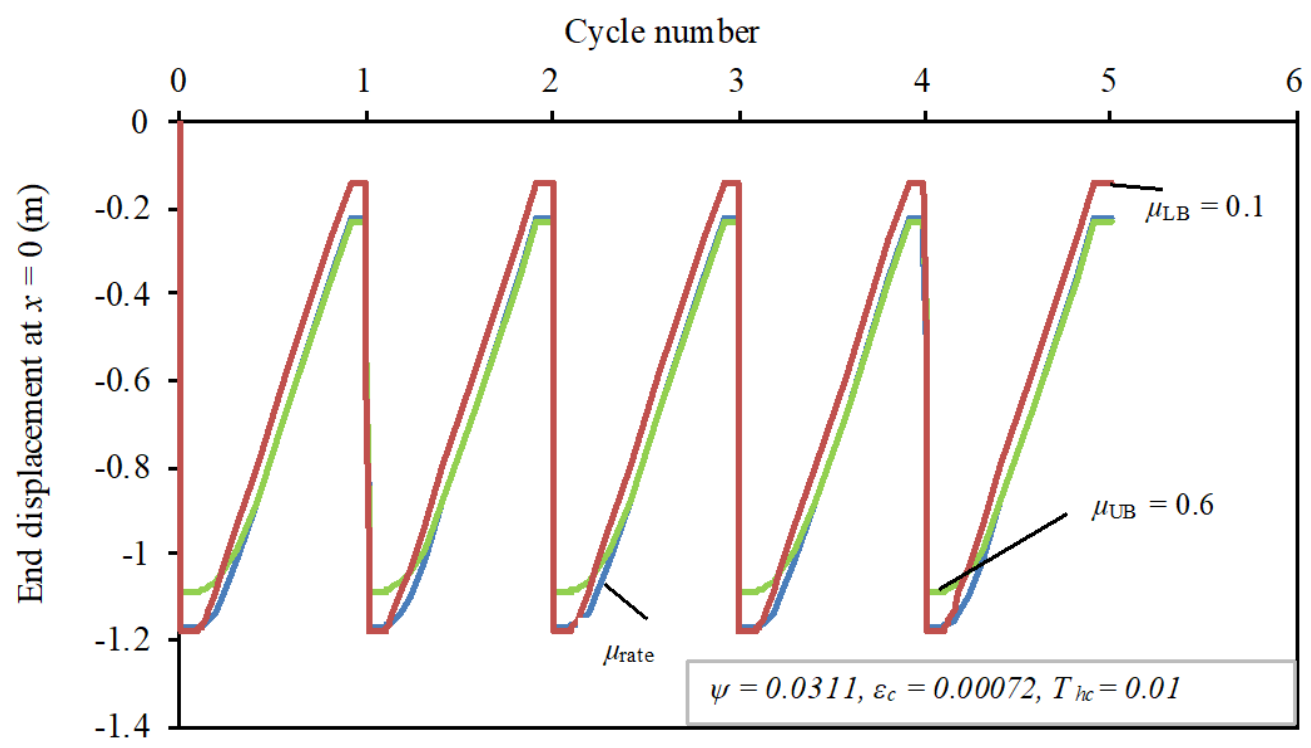

Figure 8: End displacement for drained, undrained and rate models for flat seabed

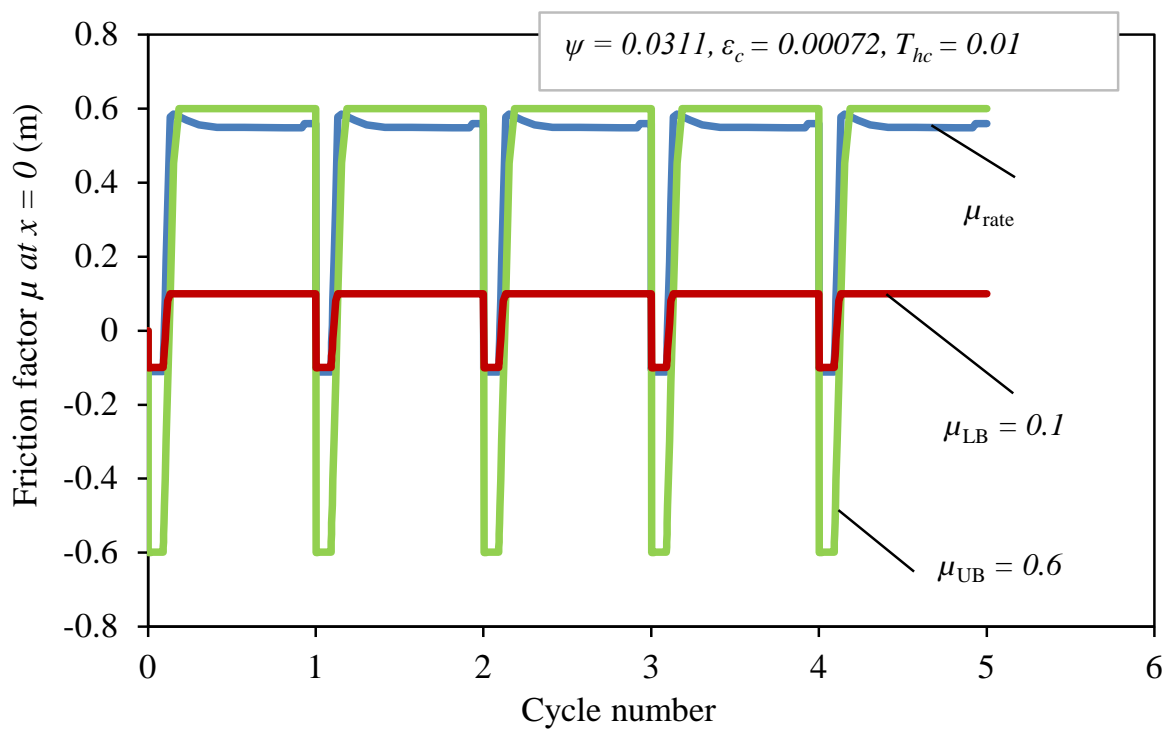

Figure 9: Mobilised friction at $\mathrm{x}=\mathrm{0}$ for drained, undrained and rate models for flat seabed 


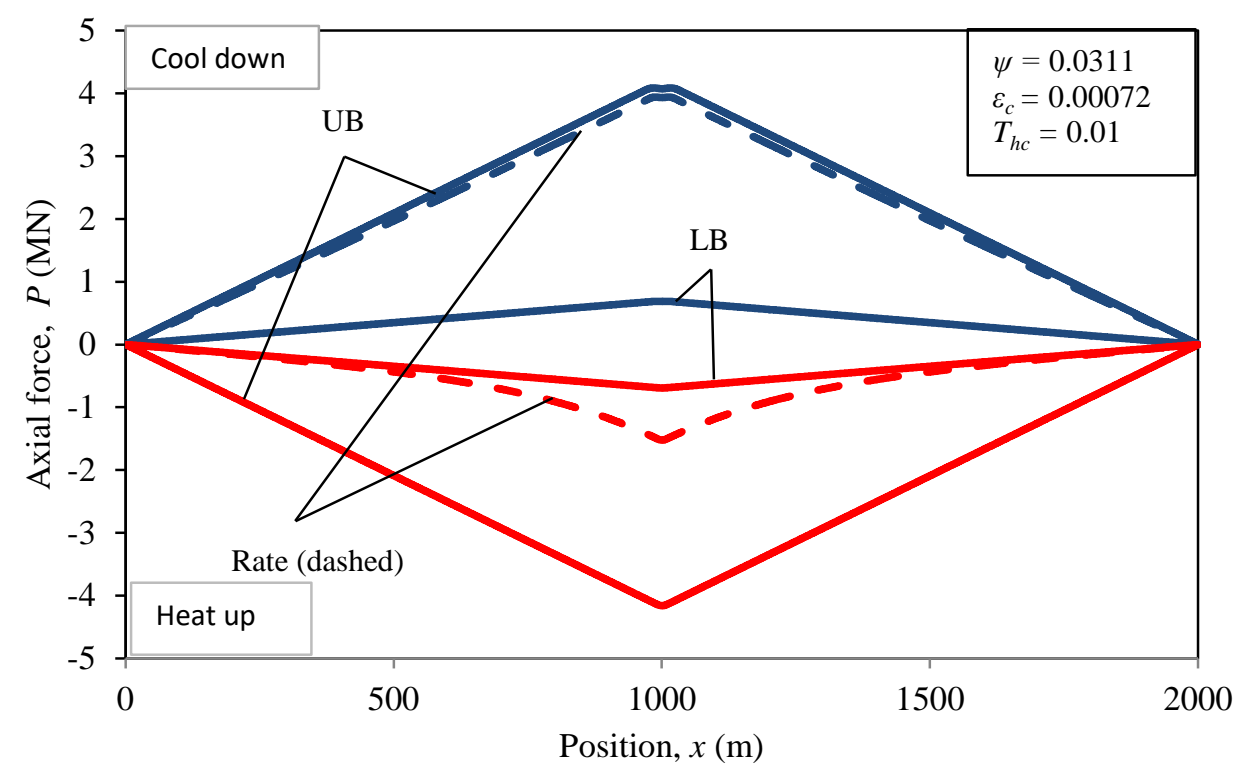

Figure 10: Force profiles for drained (UB), undrained (LB) and rate models for flat seabed

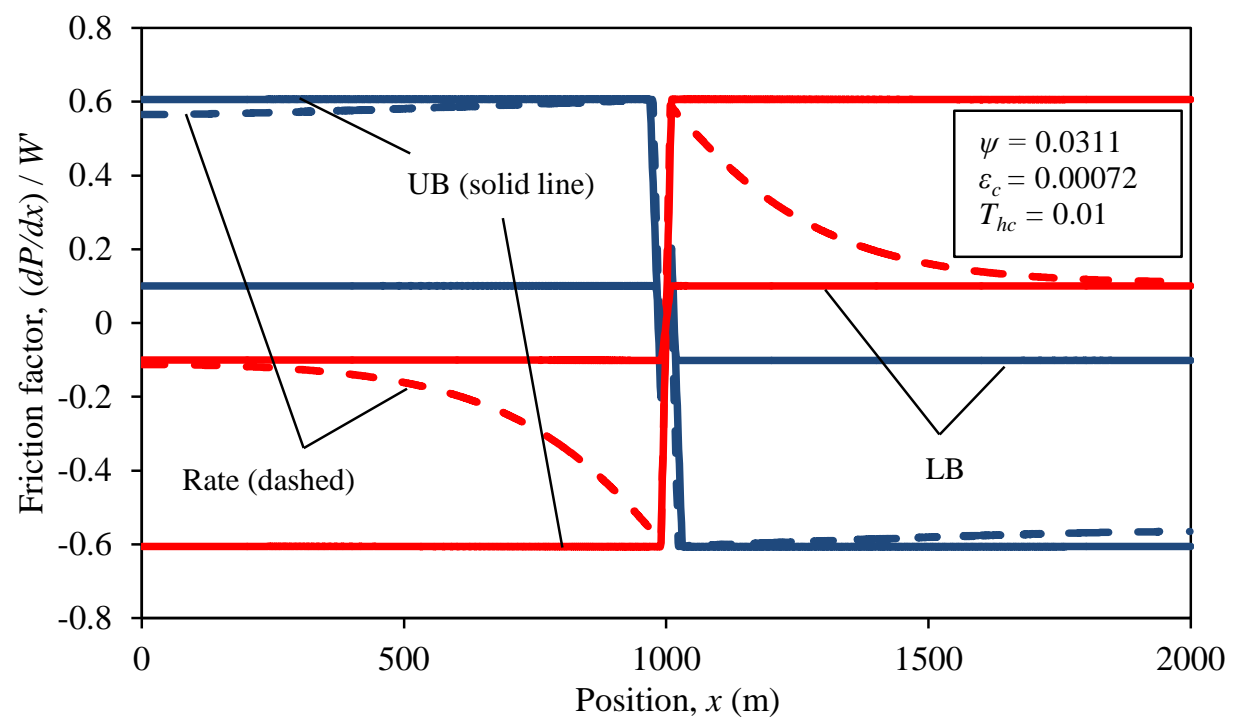

Figure 11: Friction profiles for drained (UB), undrained (LB) and rate models for flat seabed 


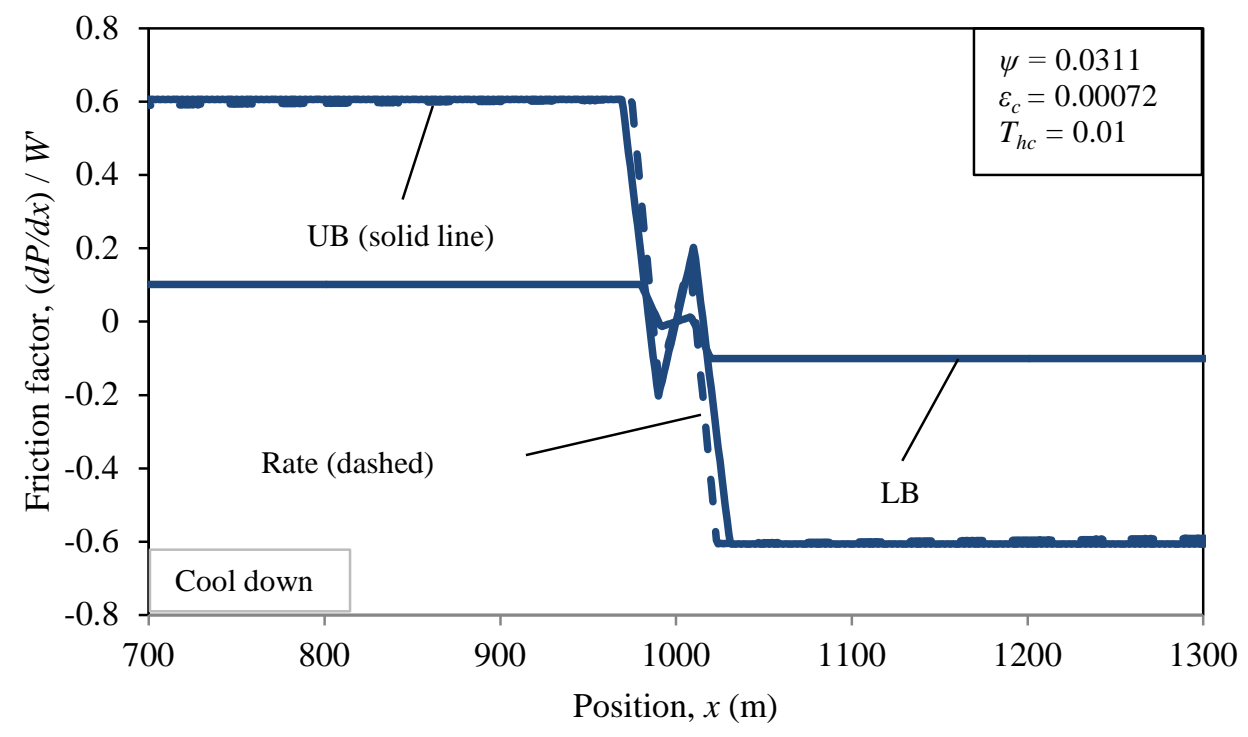

Figure 12: Enlarged view of central portion of friction profiles for flat seabed

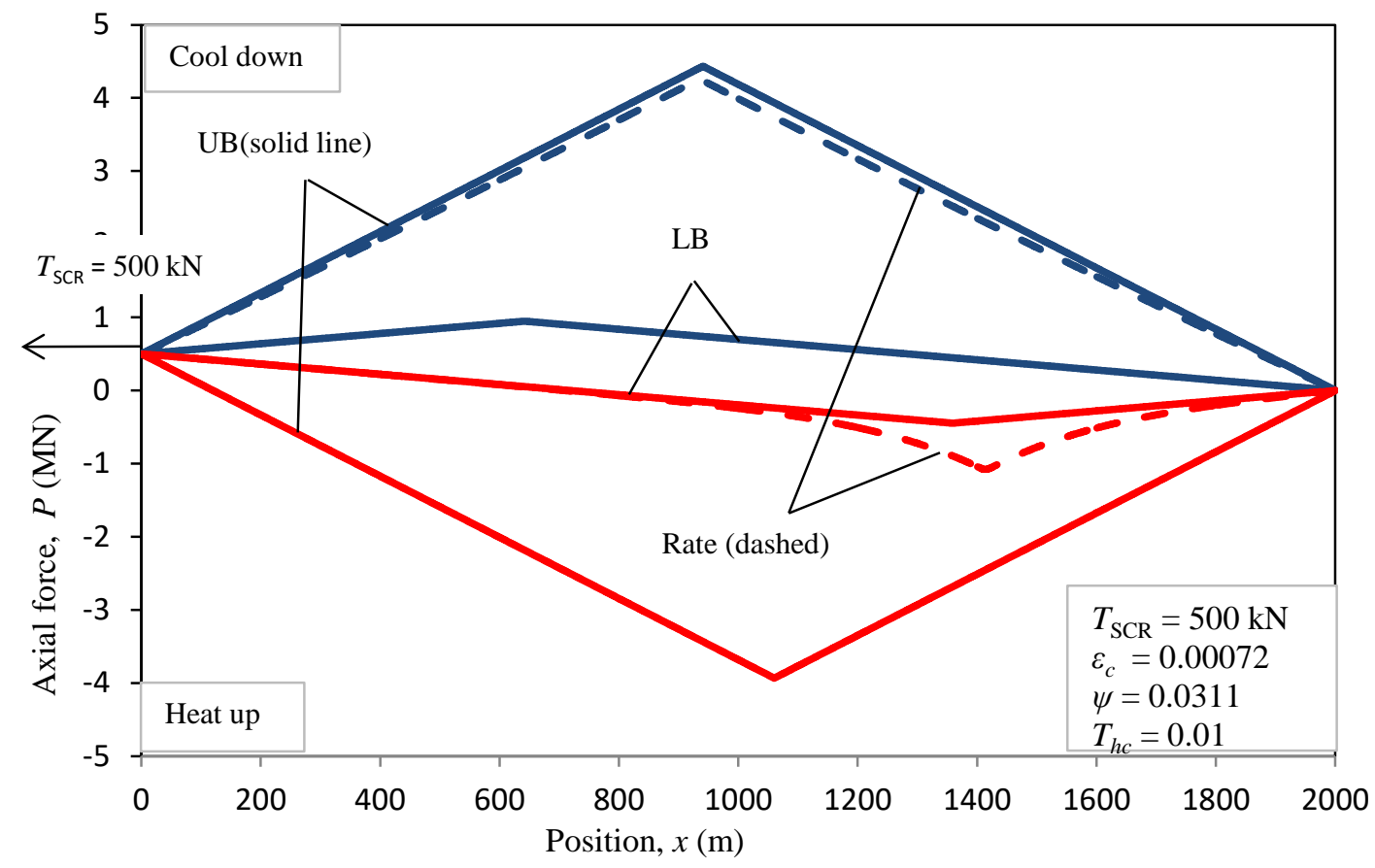

Figure 13: Force profiles for drained (UB), undrained (LB) and rate models with $T_{S C R}=500 \mathrm{kN}$ 


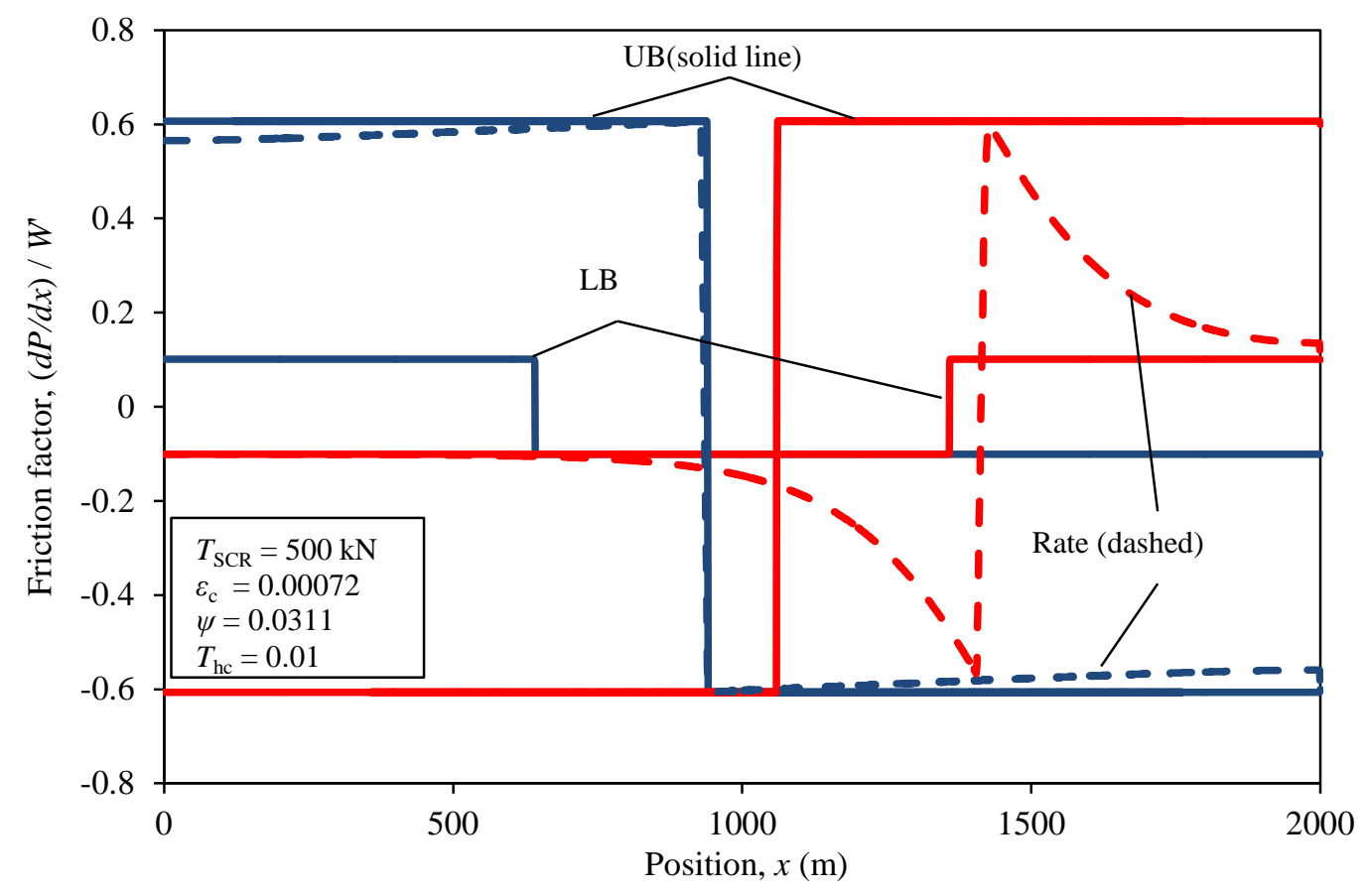

Figure 14: Friction profiles for drained (UB), undrained (LB) and rate models with $T_{S C R}=500 \mathrm{kN}$

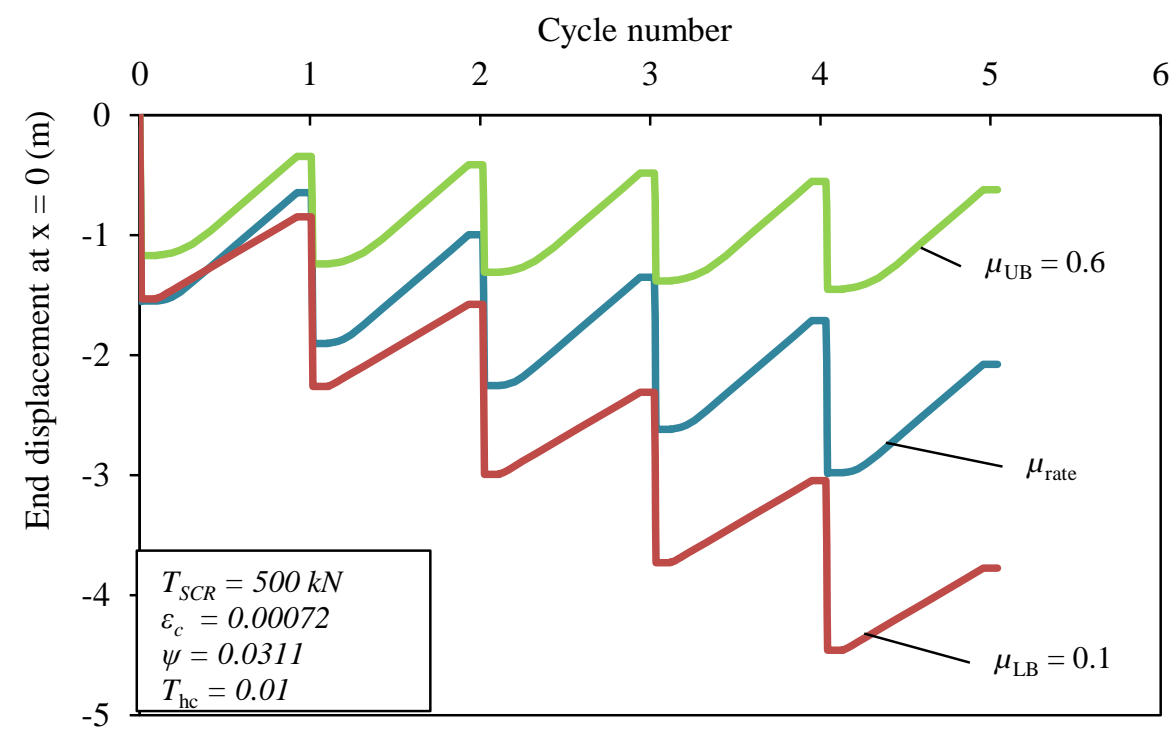

Figure 15: Walking responses for drained (UB), undrained (LB) and rate models with $T_{S C R}=500 \mathrm{kN}$ 


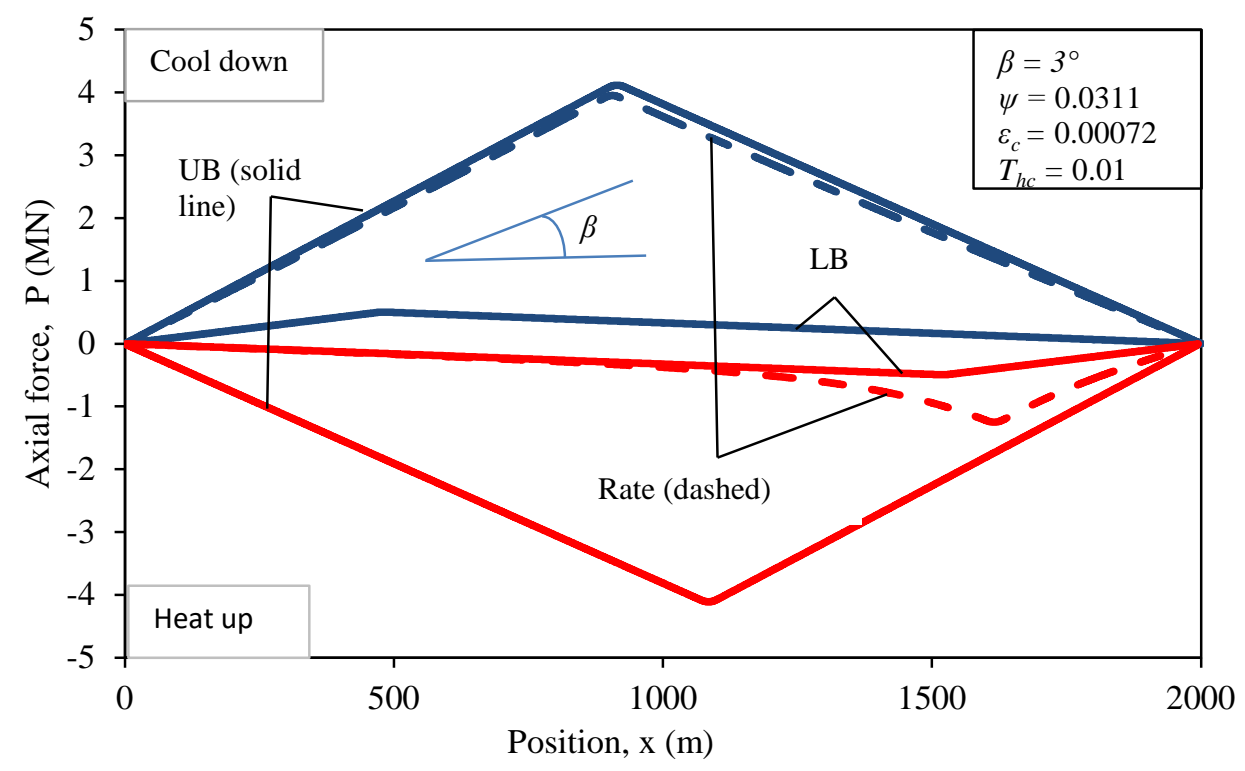

Figure 16: Force profiles for drained (UB), undrained (LB) and rate models for sloping seabed with $\beta=3^{\circ}$

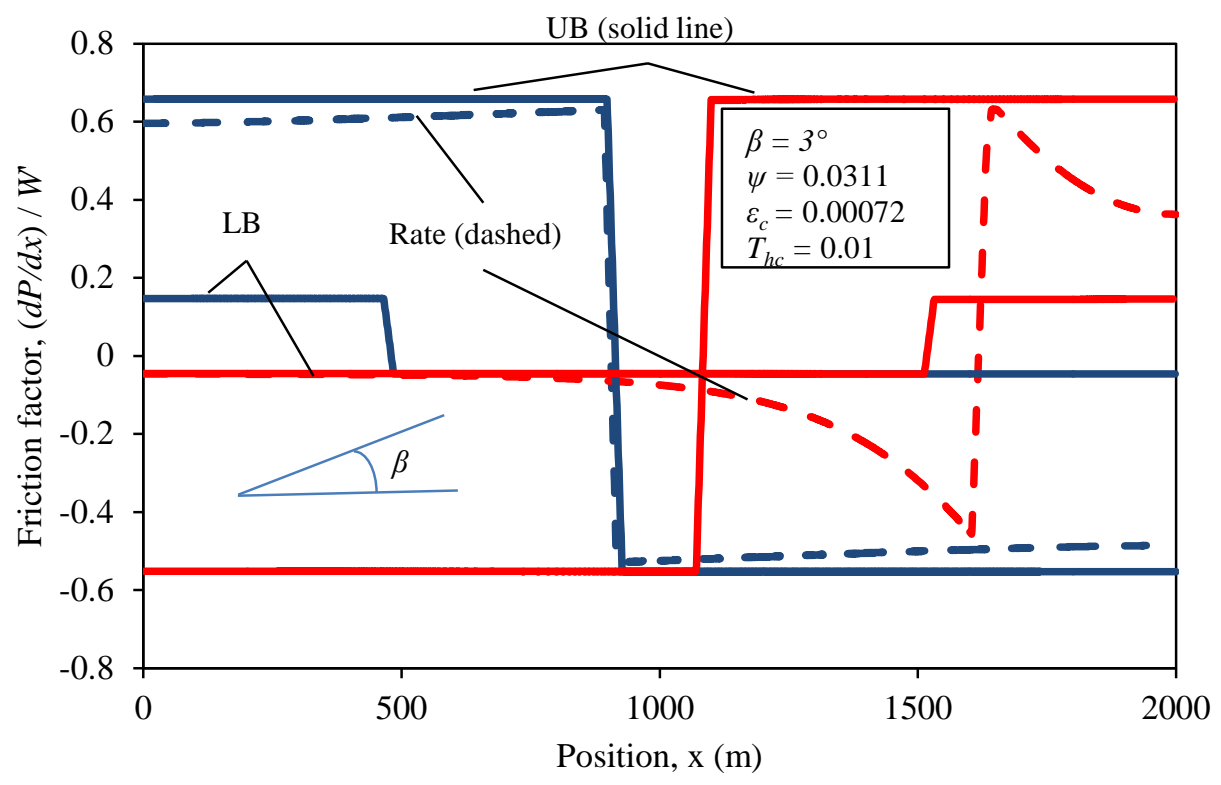

Figure 17: Friction profiles drained (UB), undrained (LB) and rate models for sloping seabed with

$$
\beta=3^{\circ}
$$




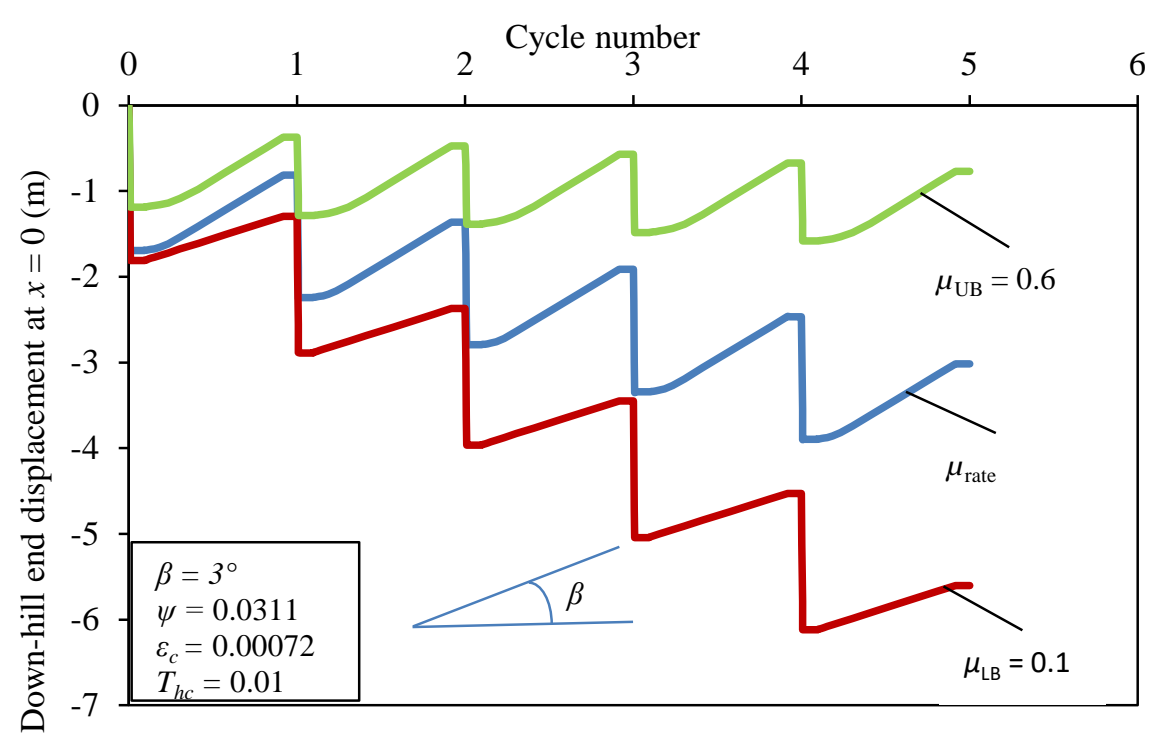

Figure 18: Walking response for drained (UB), undrained (LB) and rate models for sloping seabed with $\beta=3^{\circ}$

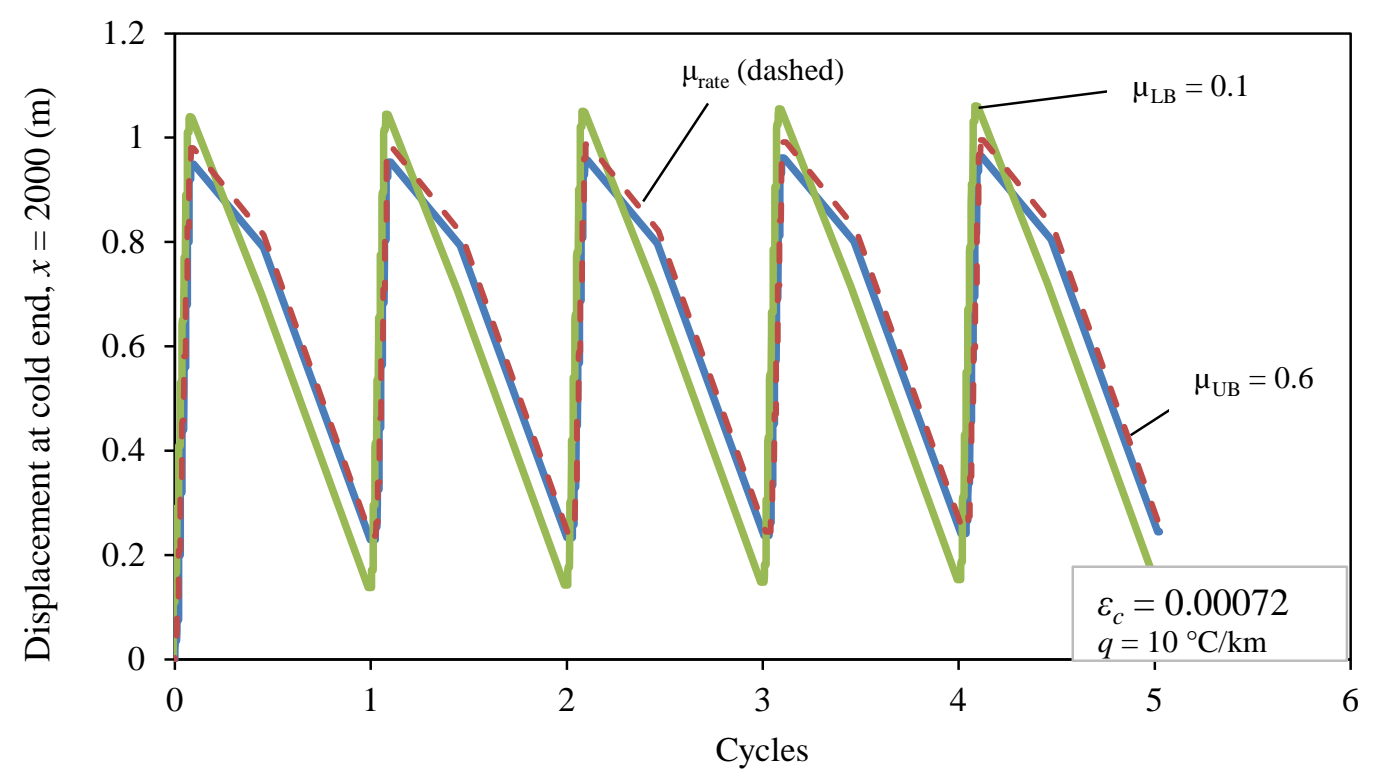

Figure 19: Walking responses for drained (UB), undrained (LB) and rate models

$$
\text { for } q=10^{\circ} \mathrm{C} / \mathrm{km}
$$




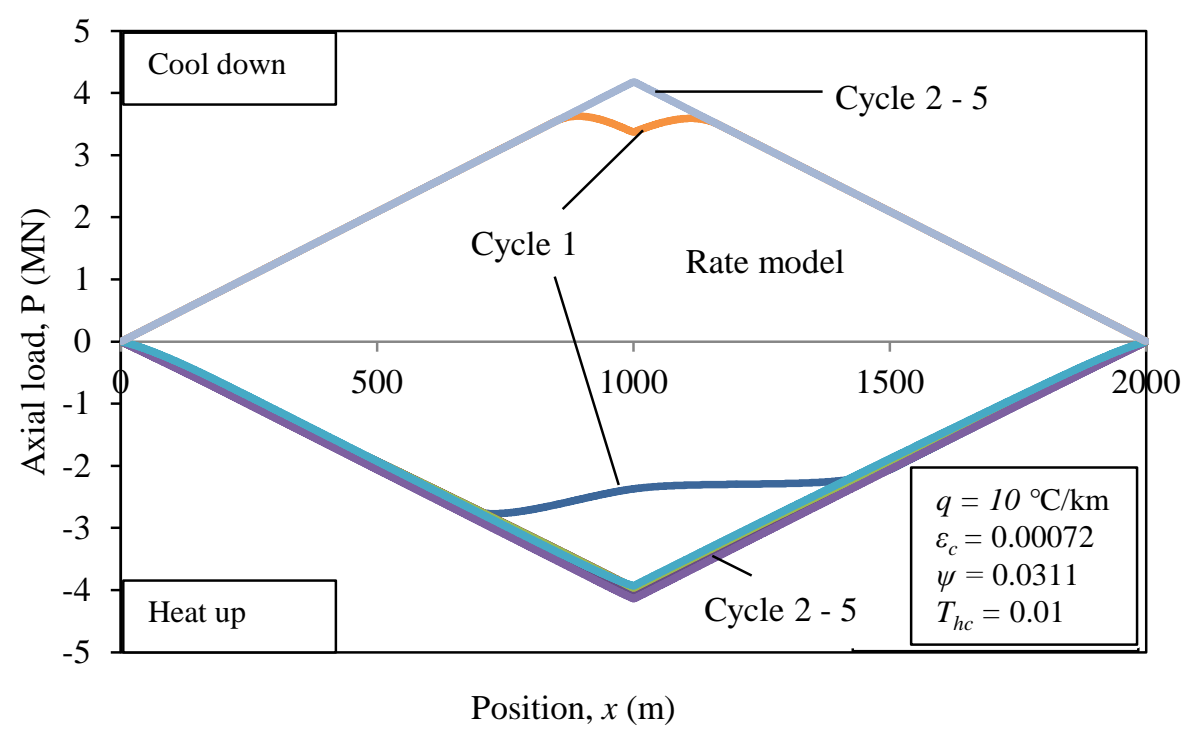

Figure 20: Force profiles for, $q=10^{\circ} \mathrm{C} / \mathrm{km}$

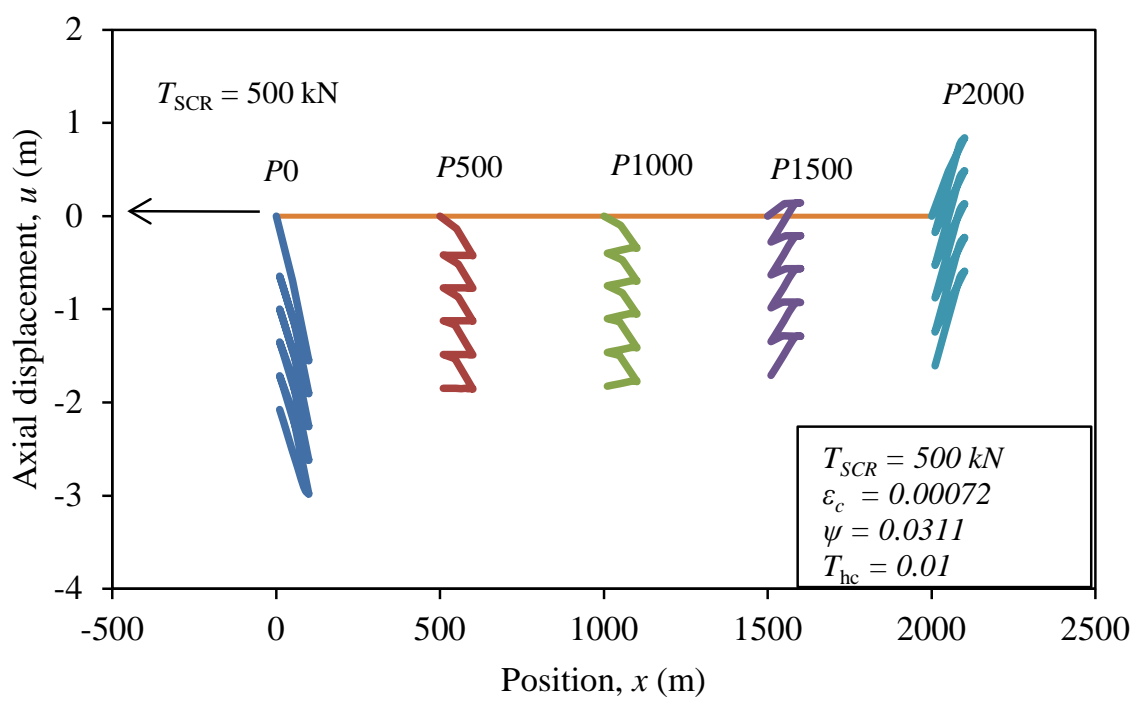

Figure 21: Distributed displacements with rate model for SCR tension, $T_{S C R}=500 \mathrm{kN}$ 


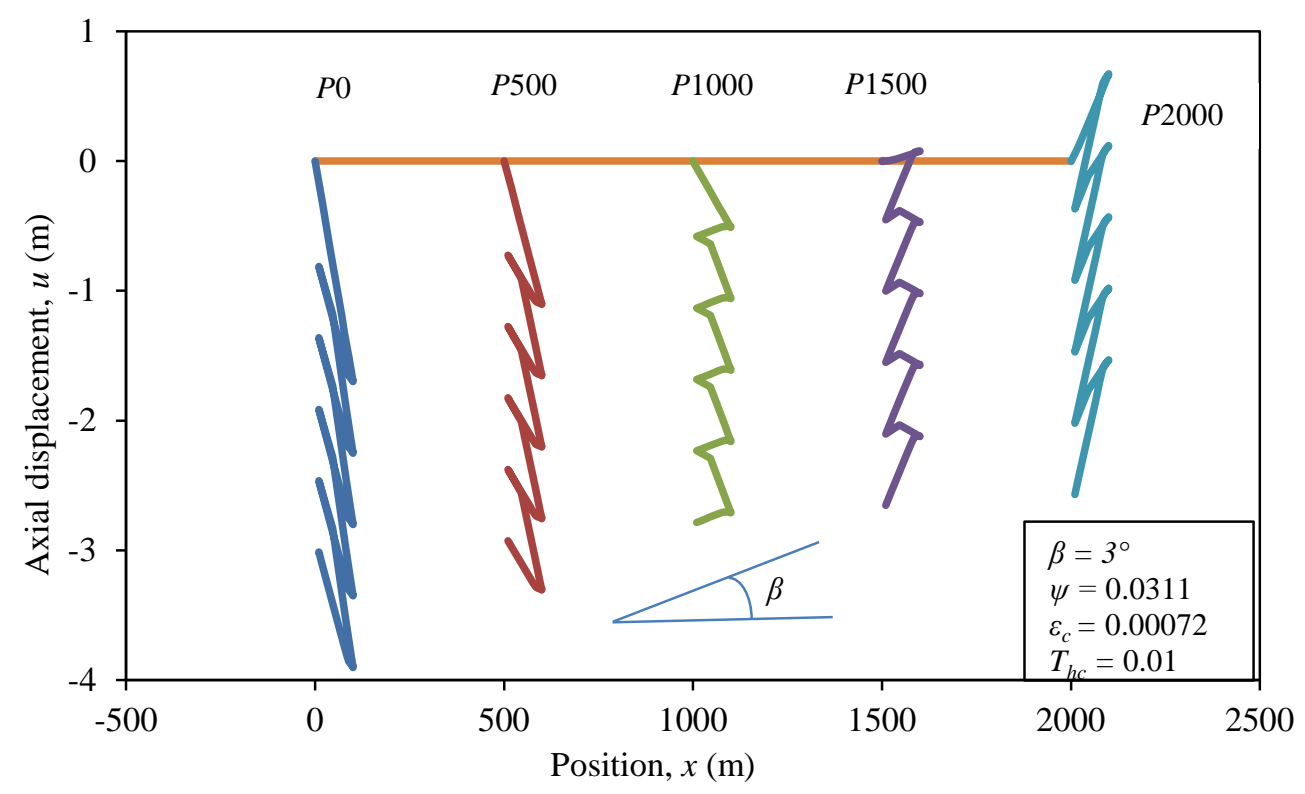

Figure 22: Distributed displacements with rate model for seabed slope, $\beta=3^{\circ}$

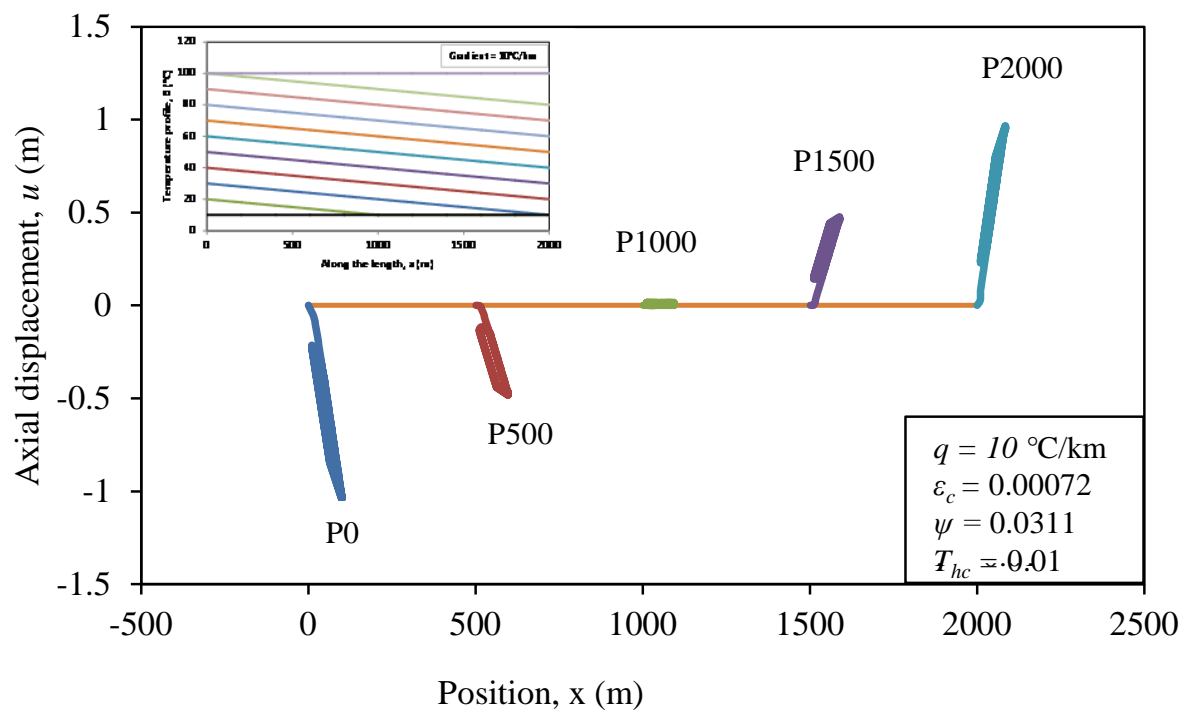

Figure 23: Distributed displacements with rate model for thermal transient, $q=10^{\circ} \mathrm{C} / \mathrm{km}$ 


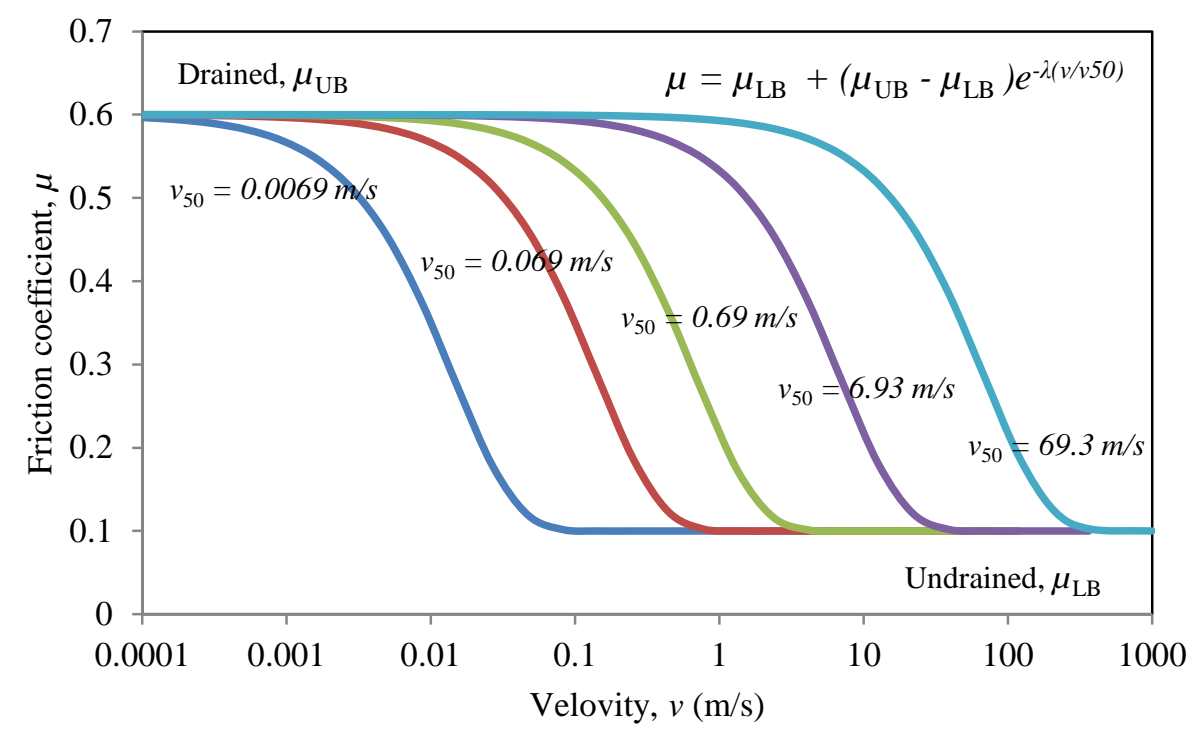

Figure 24: Range of friction models used for numerical parametric study

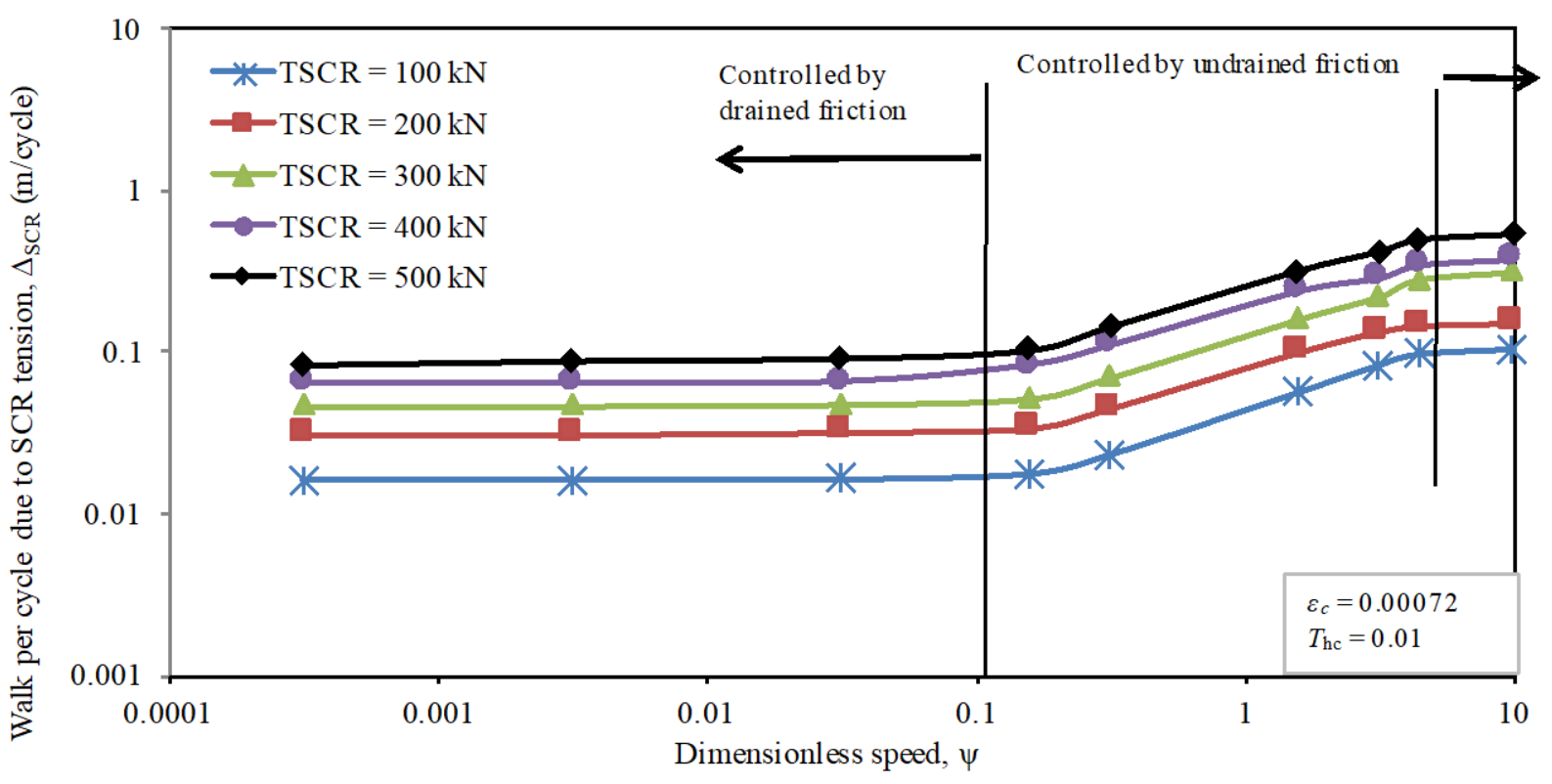

Figure 25: Effect of dimensionless velocity on walking rate for SCR tension 


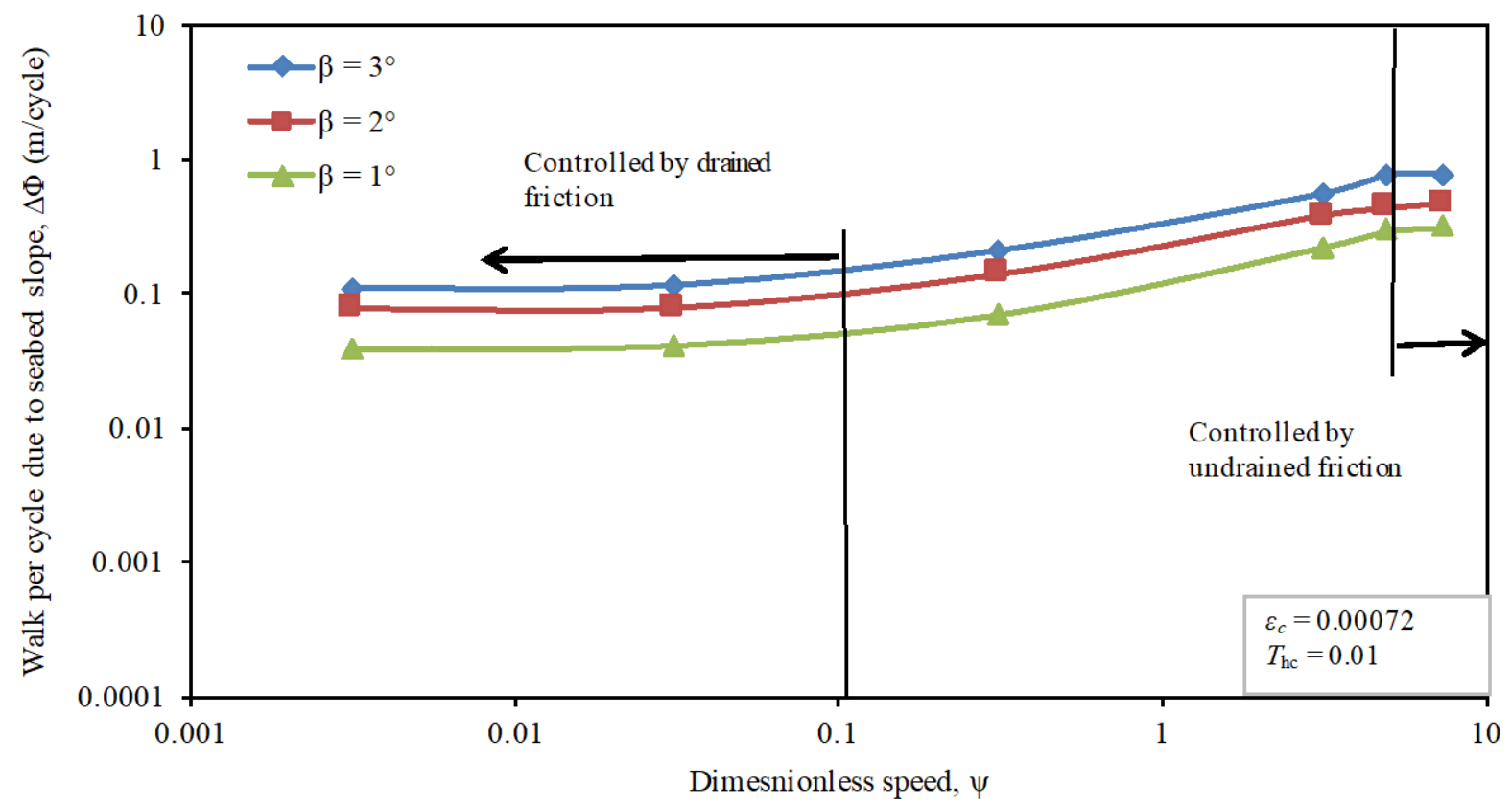

Figure 26: Effect of dimensionless velocity on walking rate for seabed slope

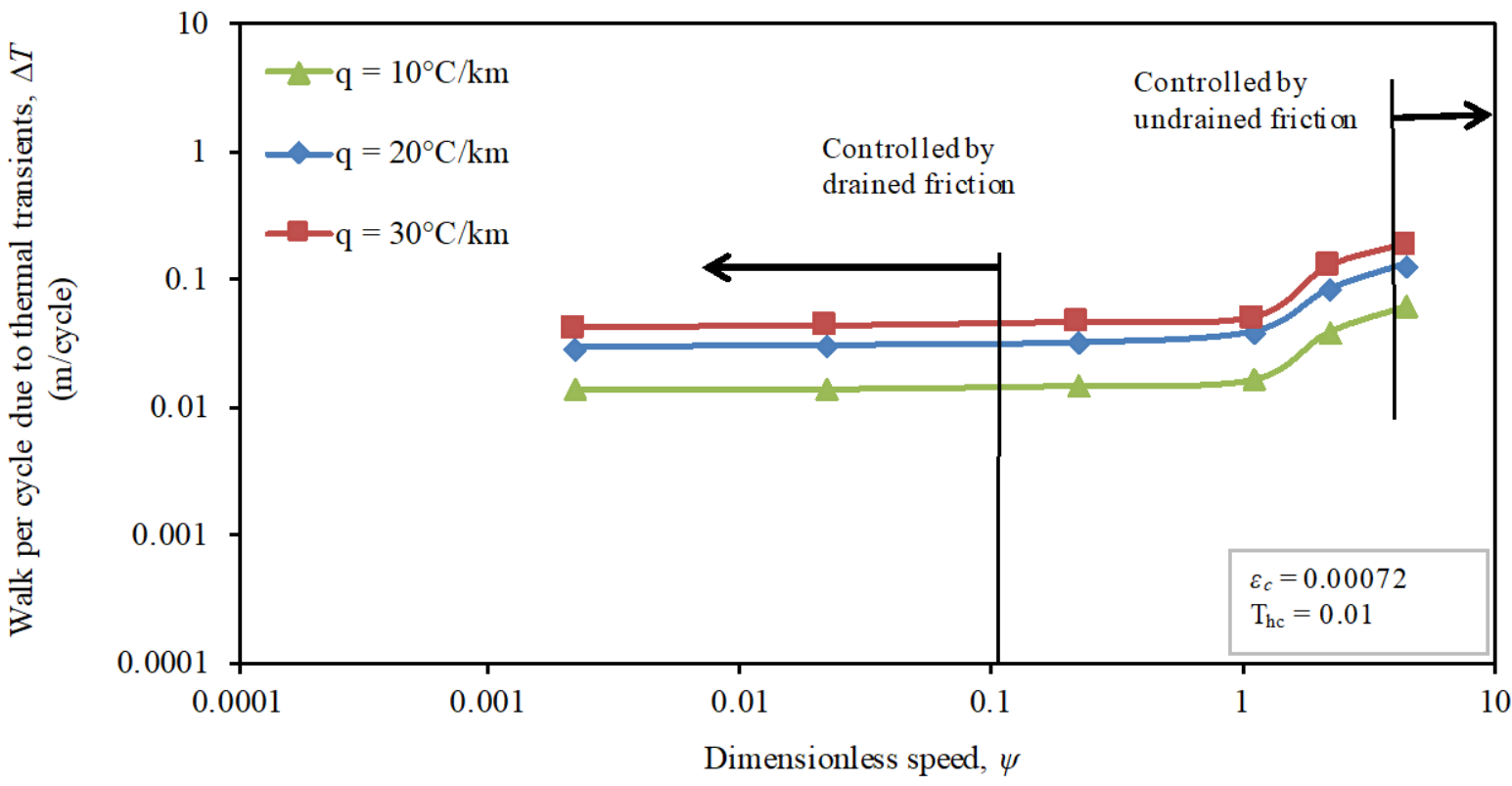

Figure 27: Effect of dimensionless velocity on walking rate for thermal transients 
Controlled by undrained friction

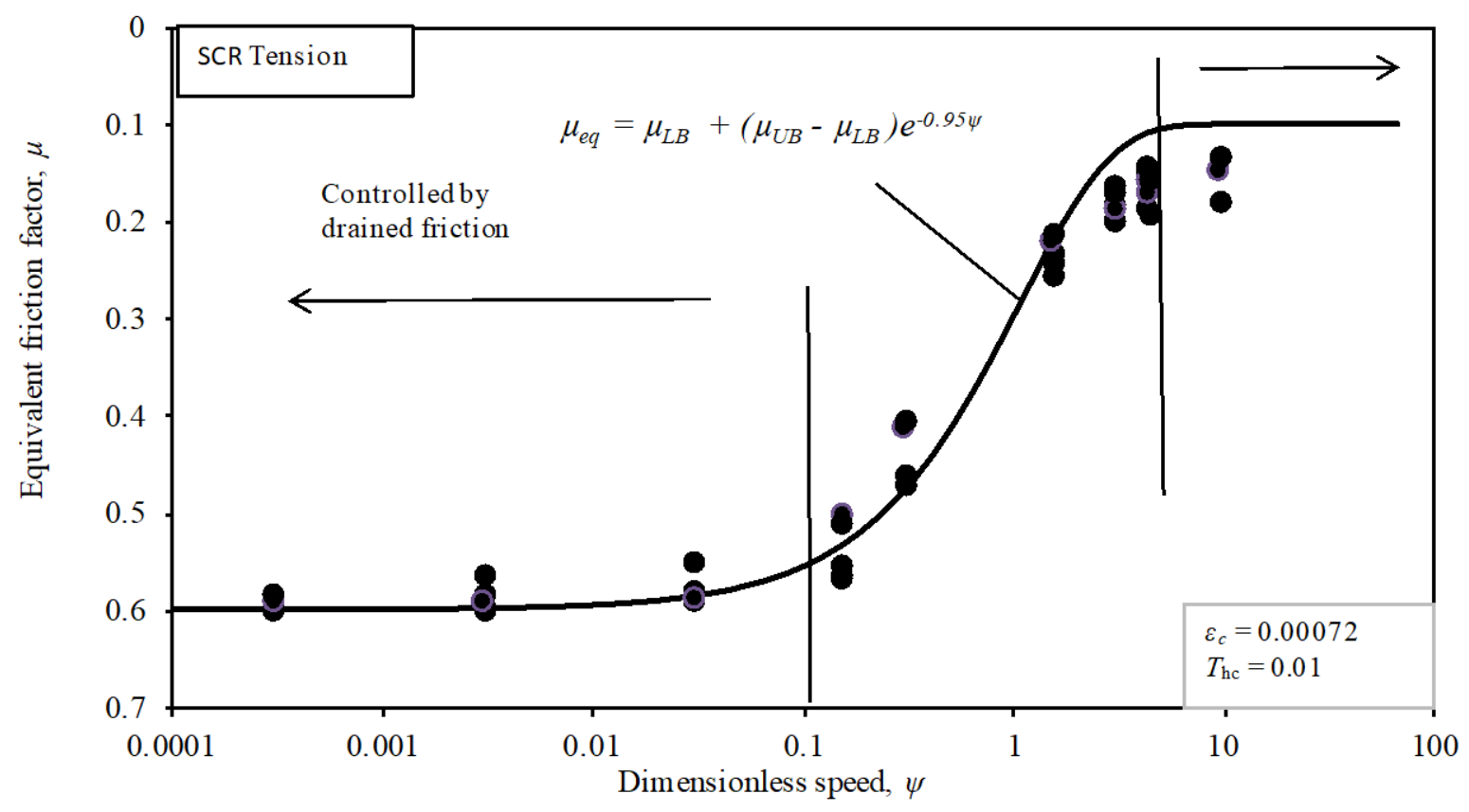

Figure 28: Equivalent friction model for SCR tension cases

Controlled by undrained friction

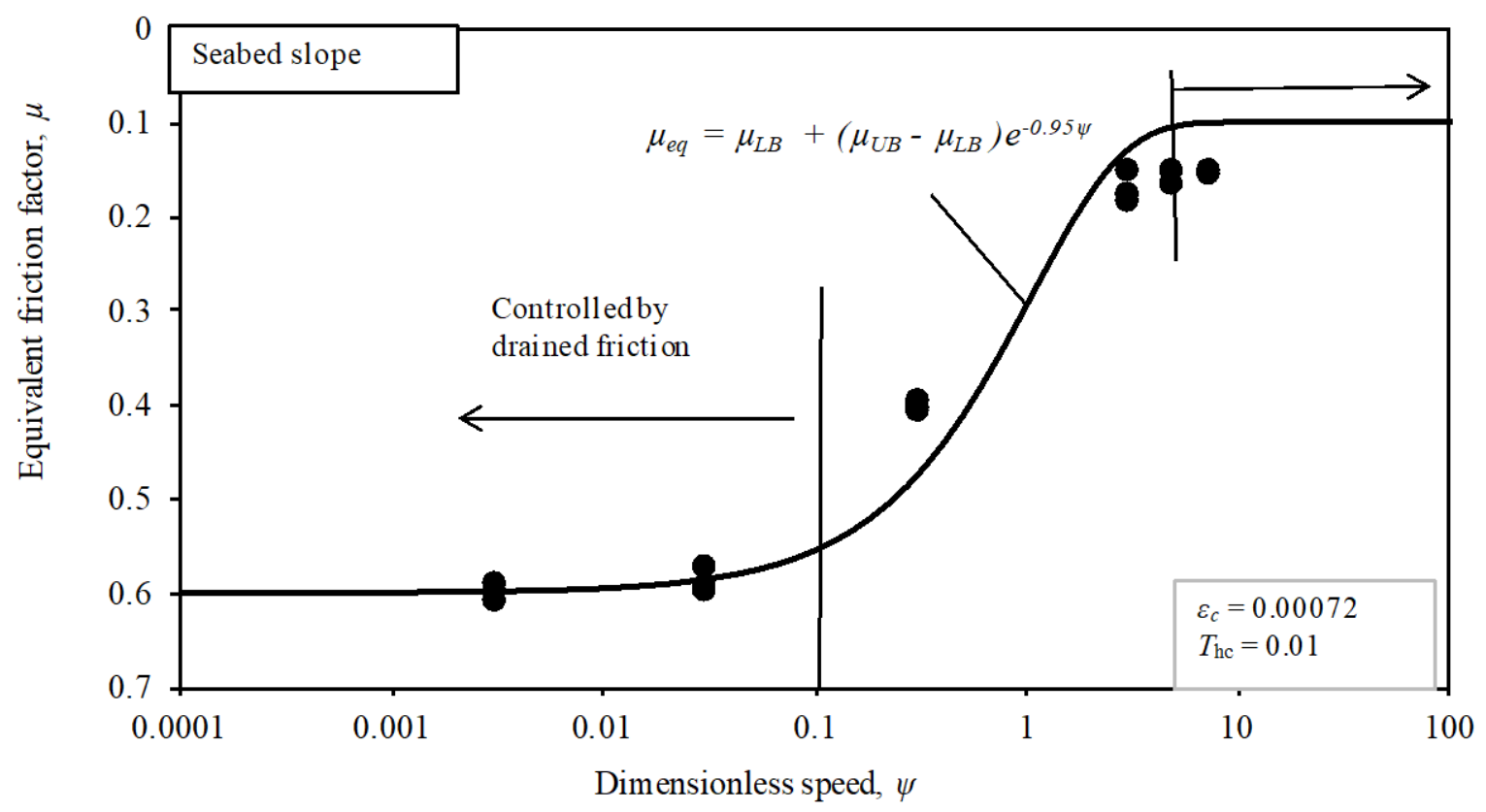

Figure 29: Equivalent friction model for sloping seabed cases 


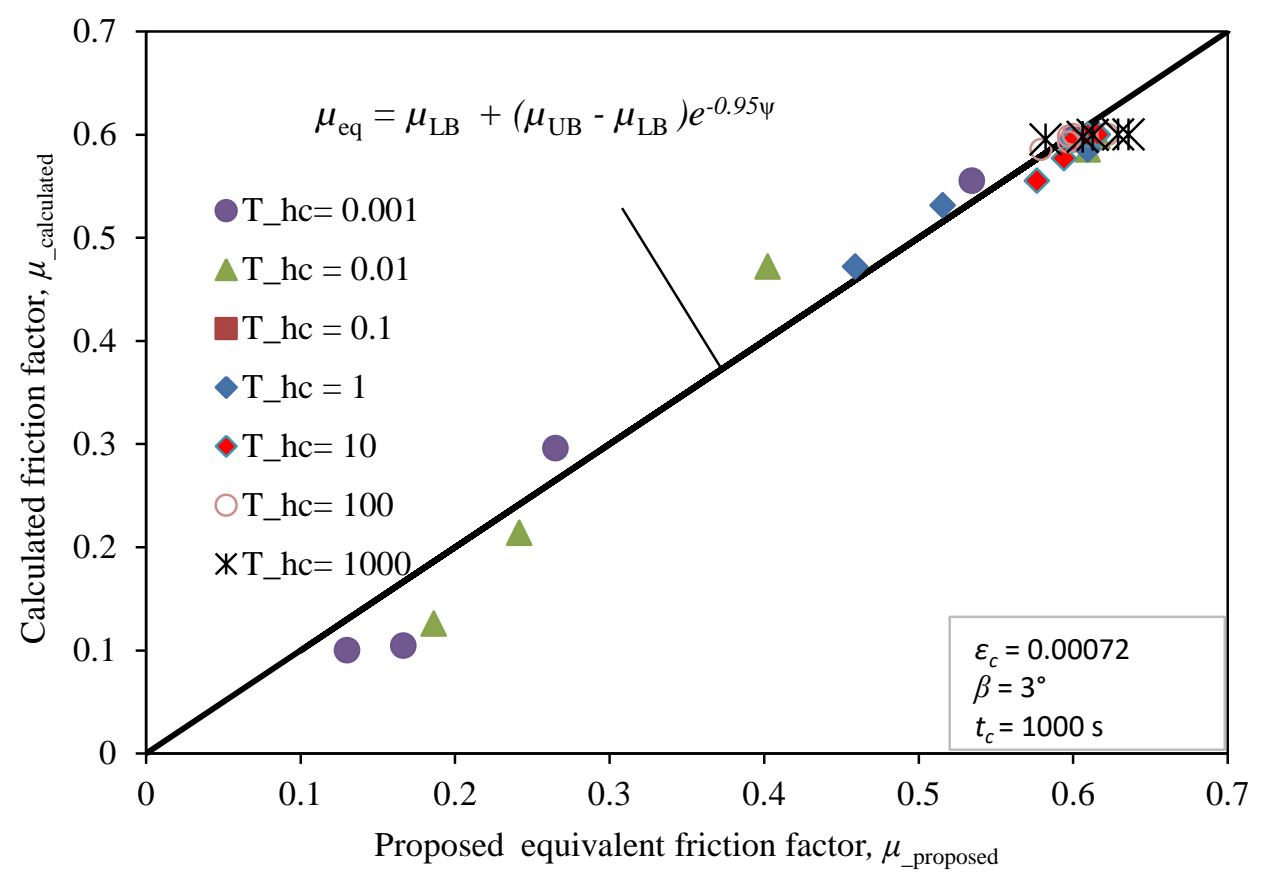

Figure 30: Comparison between proposed and calculated friction factors for varying $T_{\mathrm{hc}}$

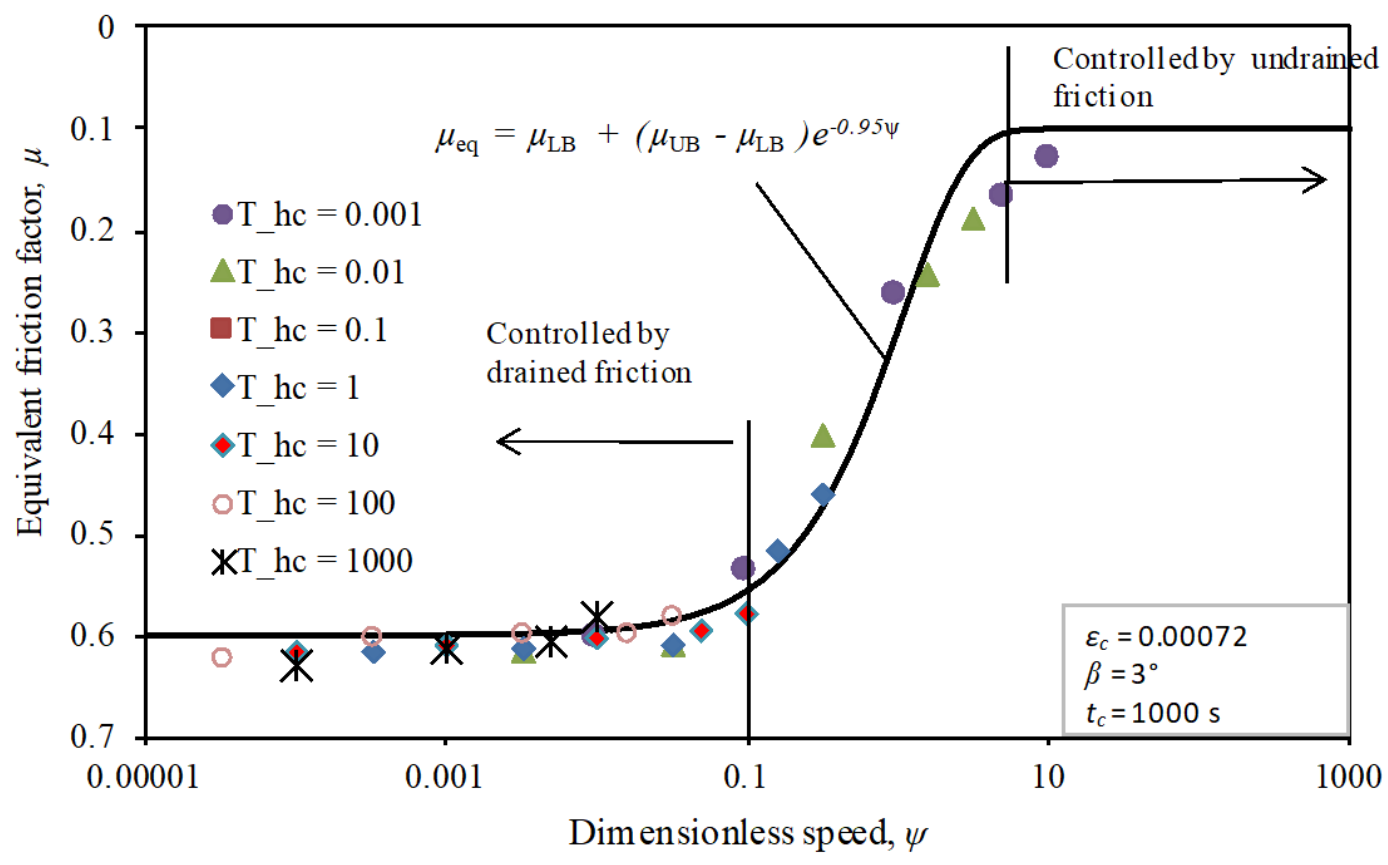

Figure 31: Equivalent friction model for cases with varying ratios of heating and cooling times, $T_{\mathrm{hc}}$ 


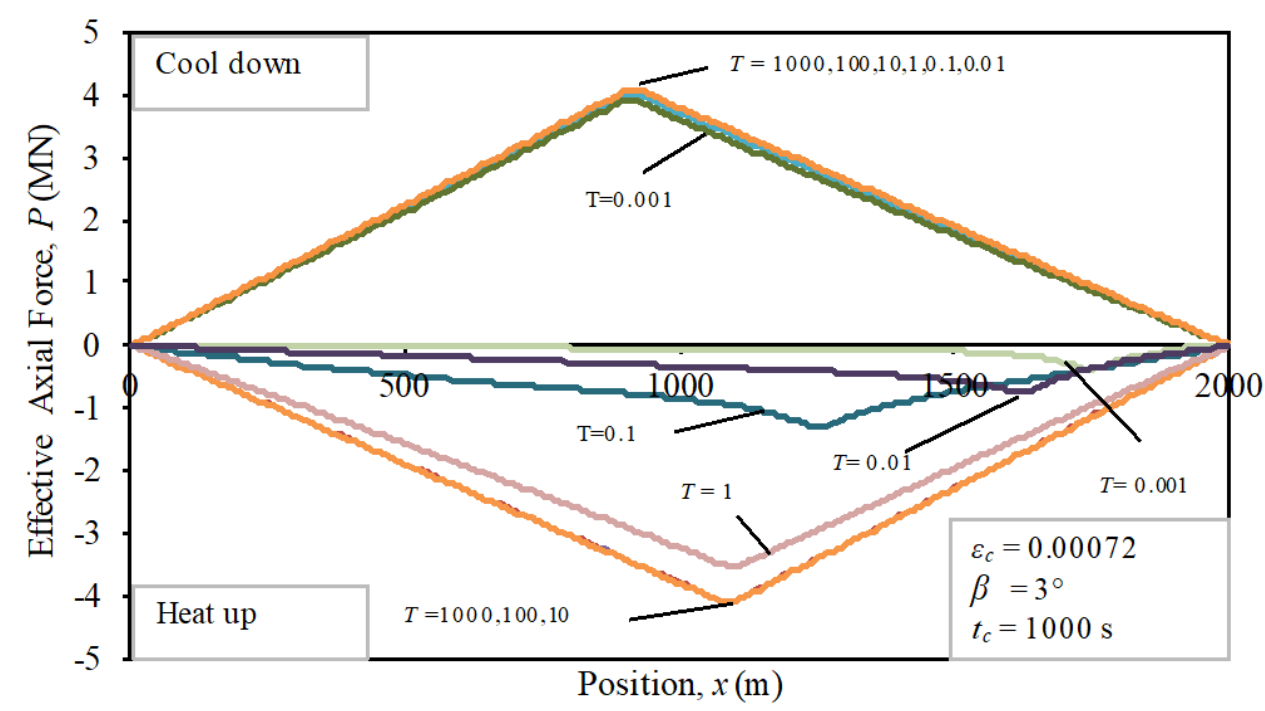

Figure 32: Comparison of force profiles for various ratios of heating and cooling times, $T_{\mathrm{hc}}$

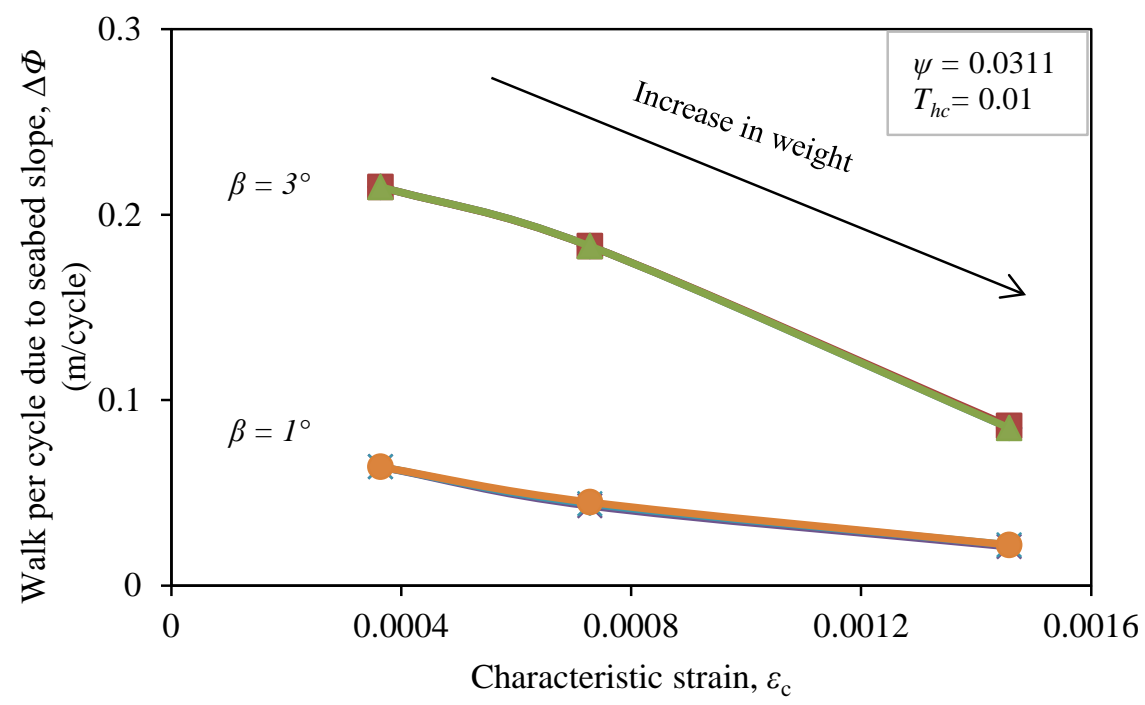

Figure 33: Effect of characteristic strain on walking rate of pipe for various weights 